\title{
The FluxMax Approach for Simultaneous Process Synthesis and Heat Integration: Production of Hydrogen Cyanide
}

\author{
Georg Liesche ${ }^{\mathrm{a}}$, Dominik Schack ${ }^{\mathrm{a}}$, Kai Sundmacher ${ }^{\mathrm{a}, \mathrm{b}}$ \\ ${ }^{a}$ Max Planck Institute for Dynamics of Complex Technical Systems, Department Process Systems \\ Engineering, Sandtorstr.1, D-39106 Magdeburg, Germany \\ ${ }^{b}$ Otto-von-Guericke-University Magdeburg, Department Process Systems Engineering, Universittsplatz 2, \\ D-39106 Magdeburg, Germany
}

\begin{abstract}
Resource and energy efficiency are essential in process synthesis of chemical plants as they combine economic with ecological benefits. The two main targets of the process synthesis problem - mass and energy flux optimization - are typically split into two steps: single unit optimization and subsequent energy integration preventing the identification of the globally optimal solution. This article presents a single-step procedure for resource-efficient process synthesis through simultaneous heat and mass flux optimization called FluxMax approach which is demonstrated for the production of hydrogen cyanide (HCN). The impact of simultaneous heat integration on the optimal process structure is demonstrated and two resource-optimal processes for HCN production are identified consisting of a combination of different reactor and recycling strategies reducing total variable cost by $68 \%$. For convex objective functions, the globally most resource-efficient process is identified highlighting the potential of the FluxMax approach for site planning and retrofitting of existing plants. Keywords: Process Synthesis, Heat Integration, Energy Efficiency, Resource Efficiency, Hydrogen Cyanide
\end{abstract}

\section{Introduction}

Besides a transition to alternative feedstocks and energy sources, a global reduction of the ecological footprint of the chemical industry is the only sensible way towards a sustainable

This article has been accepted for publication and undergone full peer review but has not been through the copyediting, typesetting, pagination and proofreading process, which may lead to differences between this version and the Version of Record. Please cite this article as doi: 10.1002/aic.16554 (C) 2019 American Institute of Chemical Engineers (AIChE) Received: Sep 20, 2018; Revised: Jan 17, 2019; Accepted: Jan 22, 2019 
consumption of raw materials ${ }^{1}$. On the short and middle term, this is achievable through an increase in resource efficiency which can be separated into raw material efficiency on the one side and energy efficiency on the other side $^{2}$. Increasing resource-efficiency is often equivalent to increasing competitiveness and brings along economic benefits. As such it is an essential topic in the chemical industry. Depending on the lengthscale, different approaches may be used to increase the efficiency of a process: At the unit level, integrated process units such as reactive distillation was investigated ${ }^{3,4}$ whereas at the process level heat integration and heat exchanger network (HEN) design were developed with the pinch analysis as the most prominent example ${ }^{5}$. The concept of a pinch point that serves as an identification of the lower bound of utility consumptions has been also applied to mass or specific species' pinches ${ }^{6}$. The identification of the most resource-efficient process is achievable via the following approaches: In non-optimization based approaches different process alternatives are analyzed and compared. These approaches include for example life-cycle analyses, definition and evaluation of processes along key performance indicators and exergy analyses that are nowadays integrated in process simulators such as Aspen ${ }^{7,8,9,10}$. On the other hand, there are optimization-based approaches that formulate the process synthesis problem as nonlinear optimization problems (NLP), mixed integer linear (MILP) or mixed integer nonlinear optimization problems (MINLP) $)^{11,12}$. There are several process synthesis examples where heat integration is not a priori because it not of key concern. This is the case if participating process units operate at near-ambient or equal temperatures e.g. in biotechnological applications ${ }^{13,14,15}$. In most industrially-relevant scenarios, however, neglection of heat integration may lead to wrong process design decisions. Within the computer-aided process engineering community, there are two approaches in order to account for heat integration in the process synthesis problem. The first approach is a sequential approach where the process synthesis problem is solved in two consecutive steps: a design step where the overall synthesis pathway is optimized and an integration step where energy is integrated 
e.g. via a pinch analysis ${ }^{16,17,18,19}$. Nowadays, there is a large community that investigates an expansion of HEN towards work and heat exchanger networks (WHEN) where waste heat is upgraded to electricity via organic Rankine cycles $^{20,21,22,23,24}$. The separation of the design and integration problem is generally easier to solve because the number of constraints is smaller compared to the combined optimization problem. However, it does not necessarily provide an overall optimal solution.

Therefore, the second approach is to combine the process synthesis and heat integration in a single step ${ }^{25,11,26}$. The fundamental idea of the Duran-Grossmann model is to include all feasible and non-feasible pinch combinations as potential candidates and to identify the feasible pinch combination through maximization of overall utility requirements. This is formulated as additional inequality constraints in the overall MINLP process synthesis problem. Refinements include the treatment of large problems via a split of all heat flows in different zones where heat is exchanged separately as well as extensions with regards to fixed and variable temperature limits as well as accurate HEN design and area calculations ${ }^{27,28,29,30,31}$. Latest developments include a systematic step-wise approach of the synthesis or extension to power-plant applications where the assumption of constant utility temperatures is not applicable ${ }^{32,33}$.

The major disadvantage of the Duran-Grossmann formulation is that the complexity of the inequality constraints of the MINLP increases exponentially with the number of heat flows in the system making it necessary to split heat integration into zones for example. Another potential disadvantage is that the solution of the integrated process synthesis and heat integration problem requires the solution of a MINLP where convergence and optimality depend to a large extent on the nonlinearities of the underlying model, heat flows and the objective function.

Besides the inclusion of the heat integration problem into the synthesis problem in the form of additional inequality constraints of the MINLP, simultaneous process synthesis and 
heat integration has been recently addressed within the infinitely dimensional state space framework (IDEAS) by Pichardo and Manousiouthakis ${ }^{34}$. Despite the authors' success in identifying the reforming process which requires the least utilities, however, their final results indicate a strong increase in separation duties which they did not consider in detail. In a separate contribution Friedler et al. combined heat exchanger network synthesis with their process network synthesis approach of p-graphs ${ }^{35,36}$. Their solution entails direct heat exchange among the heat flows of the network resulting in as much as 10,227 potential heat exchanging units in their MILP example of a single reactor with three separator stages.

It is the objective of this contribution to introduce a simultaneous process synthesis and heat integration approach and to demonstrate its effectiveness for resource-efficient process synthesis using an industrially relevant example. The approach overcomes the described drawbacks of previous integrated process synthesis approaches through an effective decoupling of nonlinearities contained in the process synthesis models: the system equations - i.e. the constraints of the optimization problem - are linearized and depending on the user's requirements for the objective function one obtains a nonlinear or linear optimization problem. The flux optimization problem is formulated in such a way that integer decision variables are avoided. The approach constitutes the generalization of the linear programming (LP) formulation for the cost and energy flux distribution optimization of a chemical production network whose feasibility has already been exemplified for process unit design ${ }^{37,38,39}$. The versatility and usefulness of the FluxMax approach for design problems across different lengthscales in process systems engineering problems is demonstrated in a separate contribution while its applicability to integrated process synthesis is illustrated with the identification of the most resource-efficient process for the production of hydrogen cyanide (HCN) in this work. This case study provides an ideal example for the proposed method for two reasons: firstly, two competing reactor technologies - each involving different chemical reactions with opposite reactor and downstream characteristics exist and secondly hydrogen is a stoi- 
chiometric byproduct of both reactor types which may be recycled within the process ${ }^{40}$. As a consequence, the most raw material and energy-efficient process is best identifiable using a simultaneous process synthesis approach. The reaction equations and reaction enthalpies $\Delta_{R} h^{\ominus}$ at standard conditions are provided in Eq. (1) and both reactor types are illustrated schematically in Fig. .1.

$$
\begin{array}{rlr}
\mathrm{CH}_{4}+\mathrm{NH}_{3} \rightleftharpoons \mathrm{HCN}+3 \mathrm{H}_{2} & \Delta_{\mathrm{R}} h^{\ominus}=229 \mathrm{~kJ} / \mathrm{mol} \\
\mathrm{CH}_{4}+\mathrm{NH}_{3}+\frac{3}{2} \mathrm{O}_{2} \rightleftharpoons \mathrm{HCN}+3 \mathrm{H}_{2} \mathrm{O} \quad \Delta_{\mathrm{R}} h^{\ominus}=-627 \mathrm{~kJ} / \mathrm{mol}
\end{array}
$$

The first reactor type is applied in the Degussa route (Eq. (1a)) ${ }^{41,42}$ : HCN is synthesized from $\mathrm{CH}_{4}$ and $\mathrm{NH}_{3}$ in an endothermic reaction while the heat for the reaction is provided by combustion of hydrocarbons in an adjacent compartment. In the second process type the Andrussow reactor is employed (Eq. (1b) $)^{43,44}$. In contrast to the Degussa reactor, $\mathrm{O}_{2}$ is added directly to the reactants $\mathrm{CH}_{4}$ and $\mathrm{NH}_{3}$ resulting in an exothermic reaction that yields kinetically - but not thermodynamically - favored HCN if the contact time with the catalyst gauze is maintained sufficiently short.

The advantage of high product purity and thus raw material efficiency in the Degussa route is compensated with its high energy demand and thus low energy efficiency of the synthesis reaction whereas the contrary is the case for the Andrussow reactor. The presence of $\mathrm{O}_{2}$ in the Andrussow reactor results in the formation of undesired, carbon-consuming byproducts such as $\mathrm{CO}$ and $\mathrm{CO}_{2}$ from oxidation of the reactant $\mathrm{CH}_{4}$. These undesired byproducts require additional efforts in the downstream processing. A comprehensive list of side reactions and byproducts is reported by Waletzko and Schmidt ${ }^{45}$. In addition to the synthesis of the most resource-efficient process for the stand-alone production of $\mathrm{HCN}$, it is the target of this contribution to identify the overall resource-optimal process under consideration of energy and byproduct stream integration. 
Following an introduction to the FluxMax approach for process synthesis with simultaneous heat and mass flux optimization, the process units and key design parameters in the case study are introduced. The results are presented in two sections: At first, the identification of the most resource-efficient $\mathrm{HCN}$ synthesis process is shown leaving recycling of $\mathrm{H}_{2}$ aside and in a subsequent step, recycling pathways of $\mathrm{H}_{2}$ via energetic coupling as well as the production of reactants from the side product $\mathrm{H}_{2}$ are included in the process synthesis.

\section{The FluxMax Approach Formulation for Process Synthesis}

The underlying idea of the FluxMax Approach (FMA) is an effective decoupling of modeling nonlinearities - that originate e.g. from chemical rate expressions, temperature dependencies of transport coefficients as well as equations of state - and a subsequent flux optimization through the linear network. The methodology is structured into three steps and is illustrated in Fig. .2 (left). The decoupling of modeling nonlinearities is achieved via a discretization of the thermodynamic state space into thermodynamic state points in the first step (I). These discretized state points are connected through elementary process functions in a second step (II) as shown in Fig. .2 (center, left) that form a superstructure of all possible transitions within the network of discretized state points. In a last step the flux optimization problem from the initial to the final state point is solved. The elementary process functions (EPF) methodology addresses the same transition problem from an initial to a final state point but identifies the optimal trajectory in the thermodynamic state space via the solution of a dynamic optimization problem as was shown for catalytic and multi-

phase reactor design ${ }^{46,47,48}$. The advantage of the FMA is that any type of transition can be easily considered as shown previously for reactor design and in this contribution with the application of the FMA for simultaneous process synthesis and heat integration ${ }^{39}$. Step I and II in Fig. .2 are closely linked and their order is not strictly defined. In contrary to the reactor design example where the thermodynamic grid was defined a priori, the discretiza- 
tion grid of the simultaneous process synthesis and heat integration example results from the modeling of transitions among state points. This modeling of transitions corresponds to modeling of process units that are either described by physical shortcut or rigorous unit models or data driven based on experimental or plant data (Fig. .2 center right).

The formulation of the second step results in a superstructure that contains all state points as well as connecting process functions. In this manner the process synthesis problem is transformed into a flux optimization problem on a network represented by a directed graph (digraph). The third step (III) is the formulation and solution of the flux optimization problem (Fig. .2 bottom left and right). Having decoupled all nonlinearities of process functions results in a convex linear feasible region because constraints of the optimization problem are linear in terms of the fluxes that are decision variables. Therefore, if a convex objective function is selected, a convex optimization problem is obtained. The strategy of a linear feasible region for process synthesis has been addressed previously within the IDEAS framework where the synthesis problem is split into a process operator and a distribution network section and the operator - which represents the unit operations - is linearized often requiring a reformulation of the process synthesis problem ${ }^{49,34,50}$. Whereas the key target within the IDEAS approach is to identify the global lower bound e.g. the mass or heat pinch point of a process through iteratively increasing the grid points within their process operators, the applicability of the FluxMax approach is more general: its elegant formulation and discretization of the entire state space instead of the process operators leading to a network flow problem enables a direct application of the approach without reformulation or dimensional reduction of the process synthesis problem. An additional advantage of this formulation is the applicability across scales as was shown previously at the process unit and plant level ${ }^{38,39}$. Through this versatility, the FluxMax approach can either be used for the identification of the globally optimal process for a chemical production system or for retrofitting and process intensification of existing processes using a relatively coarse grid as shown in the case study 
in this contribution.

\section{Digraph Representation of the Process Network Flux Problem}

The digraph representation of the chemical process network consists of nodes and edges where the nodes represent storage or transformation of chemical substances or energy and the edges allow for mass and energy fluxes between the nodes. In contrast to the p-graph approach by Friedler et al. where material and operating nodes are defined, four distinct types of nodes (or vertices) are distinguished ${ }^{51}$ : The first group of nodes constitutes the discretized points within the thermodynamic state space defined by temperature, pressure and composition coordinates. They are defined as thermodynamic substance nodes (TSN) $\mathrm{M}_{i} \in \mathcal{M}$ where $\mathcal{M}$ is the set of all TSNs that exist within the chemical process network. The second set of vertices is the set of elementary process nodes $(\mathrm{EPN}) \mathrm{E}_{j} \in \mathcal{E}$ where $\mathcal{E}$ comprises all feasible transformations among TSNs caused e.g. by chemical reactions, separation as well as a change in temperature or pressure. As a consequence TSNs can only be linked via EPNs but EPNs may have connections to two, three, or more TSNs. The third group of vertices is the set of utility nodes (UN) $\mathrm{U}_{l} \in \mathcal{U}$ where the set $\mathcal{U}$ contains all utilities within the network. UNs can link different EPNs but do not interact with discretized state space points TSNs directly. In addition to the three sets of nodes, all edges that are rated with molar, heat and work fluxes are contained in the set $\mathcal{F}$. A fourth group of nodes - the work utility nodes (WUN) $\mathrm{S}_{k}$ - are contained in the set $\mathcal{S}$. WUNs exchange work duties with process nodes but their detailed description is not relevant for the current example which consists only of work utility consuming EPNs.

\section{Thermodynamic Substance Nodes}

As just mentioned TSNs are discretized points within the thermodynamic state space as introduced in ${ }^{39}$. Consequently, a TSN is characterized by its thermodynamic coordinates for example temperature $T$, pressure $p$ and its molar composition $\left[x_{1}, x_{2}, \ldots, x_{i}\right]$. Pure sub- 
stances are therefore special cases of TSNs. For each temperature, pressure or composition change from an existing TSN via an elementary process node, a new TSN has to be introduced. Thermodynamic potentials of pure components and mixtures in particular enthalpy and entropy are calculated a priori with a (nonlinear) equation of state of choice. In order to travel from one TSN to another in the thermodynamic state space, elementary process nodes that perform the duty of elementary process functions are required as illustrated in Fig. 3 (A). Nodes represent TSNs whereas red arrows denote feasible EPFs: $\mathrm{EPF}_{1}$ is an isobaric-isothermic absorption, $\mathrm{EPF}_{2}$ an isobaric distillation, $\mathrm{EPF}_{3}$ and $\mathrm{EPF}_{4}$ represent isobaric cooling and heating respectively.

\section{Elementary Process Nodes}

Elementary process nodes $\mathrm{E}_{j}$ are introduced to describe the transformation among TSNs. EPNs link at least two TSNs via mass flux edges that are illustrated as black arrows in Fig. .3 (B) where dotted lines denote internal and full lines external fluxes. Stoichiometric process equations for TSNs are formulated analogously to chemical reaction equations for pure substances to describe the transition among TSNs via a related EPN. As indicated in the illustration, generalized stoichiometric coefficients are denoted as $\chi_{\left(\mathrm{E}_{j}\right)}^{\left(\mathrm{M}_{i}\right)}$ with the indices of the EPN and TSN that they link. In analogy to the extent of reaction $\dot{\xi}$ that is frequently used in descriptions of chemical reactors a generalized process extent number $(\mathrm{PEN}) \dot{\Gamma} \in \mathbb{R}_{0}^{+}$ is introduced that links all participating TSN of an EPN. It represents the extent of an elementary process and is defined in analogy to the extent of reaction:

$$
\mathrm{d} \dot{\Gamma}_{\mathrm{E}_{j}}:=\chi_{\mathrm{E}_{j}}^{\mathrm{M}_{i}} \mathrm{~d} \dot{N}_{\mathrm{E}_{j}}^{\mathrm{M}_{i}}
$$

where a characteristic flow of the EPN obtains the stoichiometric coefficient $\left|\chi_{\mathrm{E}_{j}}^{\mathrm{M}_{i}}\right|=1$ which is negative if the characteristic flow is inward directed and vice versa for an outward directed flow. The unit of PEN is therefore the unit of a molar flow and if this transition among TSNs 
is inactive it takes the value of zero $\dot{\Gamma}_{\mathrm{E}_{j}}=0$. It is important to note, however, that PENs should not be confused with the extent of reaction which affects the outlet composition of a reactor flow directly. Instead, the PEN is a scaling variable that enables an elegant flow problem formulation because all flows via an $\mathrm{EPN}_{j}$ are related to the unique $\mathrm{PEN}$ of $\mathrm{E}_{j}$.

\section{Utility Nodes}

The third vertex set $\mathcal{U}$ of utility nodes $\mathrm{U}_{l}$ represents the heat exchange system within a process network because heat is often not transferred between process units or streams directly but via a network of utilities such as steam lines or cooling water bodies. This has the added advantage that from a modelling perspective, a high number of heat flows can be integrated without an exponential increase in combinatorial complexity such as in the example by Nagy et al. ${ }^{36}$. Heating and cooling duties to and from elementary process nodes is therefore only supplied via suitable UNs, i.e. they must have matching temperature to fulfill the second law of thermodynamics. Surplus or demands of utilities are supplied with external heat flows denoted with full blue lines in Fig. .3. Heat integration among EPNs occurs indirectly via heat exchange with UNs. Consequently, UNs connect EPNs but not TSNs.

\section{Digraph Edges}

Based on the three sets of nodes that were introduced above for the digraph representation of a chemical process, edges that are evaluated by mass (Fig. .3 black arrows), heat (Fig. .3 blue arrows) and work (Fig. .3 red arrows) fluxes are introduced as connections among nodes. These fluxes are the decision variables of the optimization problem and constraints ensure feasibility of the results. Upon definition of a process network of interest, internal edges are connections among nodes that are responsible for the internal distribution of mass and energy whereas external edges provide external supplies to the process network. External supplies can be either work duties supplied to WUNs, heating and cooling duties supplied 
to UNs or mass fluxes supplied to or extracted from TSNs.

\section{Formulation of Node Conservation Laws}

Conservation laws for each node of the three node types TSN, EPN and UN are set up whereas no equations are required for WUNs because no work integration is considered. Based on the reaction equation notation of each elementary process function, EPN mass and energy balances are formulated. Whereas the conventional modeling of partial mass balances (PMB) requires one PMB for each pure substance, the PMBs of the digraph apply the discretized thermodynamic state space grid defined by the TSNs. Integration of Eq. (2) yields

$$
\chi_{\mathrm{E}_{j}}^{\mathrm{M}_{i}} \dot{\Gamma}_{\mathrm{E}_{j}}=\dot{N}_{\mathrm{E}_{j}}^{\mathrm{M}_{i}}-\dot{N}_{\mathrm{E}_{j}, 0}^{\mathrm{M}_{i}}
$$

Furthermore, full conversion of thermodynamic substances inside an EPN is assumed - the thermodynamic substance entering the EPN from e.g. $M_{i}$ is fully converted to a different thermodynamic substance, say $\mathrm{M}_{i+1}$ - resulting therefore in the following PMB for each TSN $\mathrm{M}_{i}$ that is connected to an $\mathrm{EPN}_{j}$ :

$$
0=-\operatorname{sgn}\left(\chi_{\left(\mathrm{E}_{j}\right)}^{\left(\mathrm{M}_{i}\right)}\right) \dot{N}_{\left(\mathrm{E}_{j}\right)}^{\left(\mathrm{M}_{i}\right)}+\chi_{\left(\mathrm{E}_{j}\right)}^{\left(\mathrm{M}_{i}\right)} \dot{\Gamma}_{\left(\mathrm{E}_{j}\right)}
$$


In addition to the PMBs, an energy balance for each $\mathrm{EPN}_{j}$ is formulated containing molar heat $(\varphi)$ and work $(\omega)$ duties.

$$
\begin{aligned}
& 0=\left(-\omega_{\left(\mathrm{E}_{j}\right)}^{\text {in }}+\omega_{\left(\mathrm{E}_{j}\right)}^{\text {out }}\right) \dot{\Gamma}_{\left(\mathrm{E}_{j}\right)}+\dot{W}_{\left(\mathrm{E}_{j}\right)}^{\text {ext, in }}-\dot{W}_{\left(\mathrm{E}_{j}\right)}^{\text {ext, out }} \\
& 0=\left[\varphi_{\left(\mathrm{E}_{j}\right)}^{\text {out }}+\left(1-\eta_{\left(\mathrm{E}_{j}\right)}^{\text {in }}\right) \omega_{\left(\mathrm{E}_{j}\right)}^{\text {in }}+\left(\frac{1}{\eta_{\left(\mathrm{E}_{j}\right)}^{\text {out }}}-1\right) \omega_{\left(\mathrm{E}_{j}\right)}^{\text {out }}\right] \dot{\Gamma}_{\left(\mathrm{E}_{j}\right)}-\sum_{\forall \mathrm{U}_{l}} \dot{Q}_{\left(\mathrm{U}_{l}\right)}^{\left(\mathrm{E}_{j}\right)} \\
& 0=-\varphi_{\left(\mathrm{E}_{j}\right)}^{\text {in }} \dot{\Gamma}_{\left(\mathrm{E}_{j}\right)}+\sum_{\forall \mathrm{U}_{l}} \dot{Q}_{\left(\mathrm{E}_{j}\right)}^{\left(\mathrm{U}_{2}\right)} \\
& \text { where } \dot{Q}_{\left(\mathrm{U}_{l}\right)}^{\left(\mathrm{E}_{j}\right)}, \dot{Q}_{\left(\mathrm{E}_{j}\right)}^{\left(\mathrm{U}_{l}\right)}, \dot{W}_{\left(\mathrm{E}_{j}\right)}^{\text {ext, out }}, \dot{W}_{\left(\mathrm{E}_{j}\right)}^{\text {ext, in }} \in \mathbb{R}_{0}^{+}
\end{aligned}
$$

The superscript of an internal heat flow $\dot{Q}_{\left(\mathrm{E}_{j}\right)}^{\left(\mathrm{U}_{\mathrm{U}}\right)}$ indicates the node from which it originates and the subscript its destination node. In Eqs. (5), the assumption is made that simultaneous work in- and outflows do not occur and all flux variables are defined as non-negative quantities. The energy balance is split into three equations in order to avoid additional entropy balances: Eq. (5a) contains work duties only. For EPNs that do not require work inor output flows such as distillation columns, this equation is omitted. The second equation (Eq. (5b)) contains the net cooling duty which is composed of three contributions for a EPN $\mathrm{E}_{j}$ : cooling duty e.g. due to condensation and cooling duties resulting from waste heat for work in- and output flows which is accounted for by means of two efficiency factors $\eta_{\left(\mathrm{E}_{j}\right)}^{\mathrm{in}}$ and $\eta_{\left(\mathrm{E}_{j}\right)}^{\text {out }}$ :

$$
\eta_{\left(\mathrm{E}_{j}\right)}^{\text {in }}:=\frac{\omega_{\left(\mathrm{E}_{j}\right)}^{\text {in, rev }}}{\omega_{\left(\mathrm{E}_{j}\right)}^{\text {in }}} \quad \text { and } \quad \eta_{\left(\mathrm{E}_{j}\right)}^{\text {out }}:=\frac{\omega_{\left(\mathrm{E}_{j}\right)}^{\text {out }}}{\omega_{\left(\mathrm{E}_{j}\right)}^{\text {out, rev }}}
$$

The third part of the energy balancing concept accounts for net heating duties (Eq. (5c)). TSNs may interact with any EPN via internal mass fluxes $\dot{N}_{\left(\mathrm{E}_{j}\right)}^{\left(\mathrm{M}_{i}\right)}$ as well as with external supplies via external mass fluxes $\dot{N}_{\text {ext, in }}^{\left(\mathrm{M}_{i}\right)}, \dot{N}_{\text {ext, out }}^{\left(\mathrm{M}_{i}\right)} \in \mathbb{R}_{0}^{+}$. PMBs for TSNs are therefore formulated 


$$
0=\sum_{\mathrm{E}_{j} \in \mathcal{E}} \operatorname{sgn}\left(\chi_{\left(\mathrm{E}_{j}\right)}^{\left(\mathrm{M}_{i}\right)}\right) \dot{N}_{\left(\mathrm{E}_{j}\right)}^{\left(\mathrm{M}_{i}\right)}+\dot{N}_{\mathrm{ext}, \text { in }}^{\left(\mathrm{M}_{i}\right)}-\dot{N}_{\mathrm{ext}, \text { out }}^{\left(\mathrm{M}_{i}\right)}
$$

Energy balances for TSNs are not required because energy balances are accounted for in the EPNs and TSNs are not linked directly.

Utility nodes are only connected via heat fluxes and therefore require no PMBs. The energy balance for each $\mathrm{UN}_{l}$ is formulated as

$$
0=\sum_{\mathrm{E}_{j} \in \mathcal{E}}\left(\dot{Q}_{\left(\mathrm{U}_{l}\right)}^{\left(\mathrm{E}_{j}\right)}-\dot{Q}_{\left(\mathrm{E}_{j}\right)}^{\left(\mathrm{U}_{l}\right)}\right)+\dot{Q}_{\left(\mathrm{U}_{l}\right)}^{\mathrm{ext}, \mathrm{in}}-\dot{Q}_{\left(\mathrm{U}_{l}\right)}^{\mathrm{ext} \text { out }} \quad \forall \mathrm{U}_{l} \in \mathcal{U}
$$

The sum of all heat fluxes entering an utility $\mathrm{U}_{l}$ - heat fluxes from elementary node $\mathrm{E}_{j}$ towards $\mathrm{U}_{l}$ and externally provided heat fluxes $\dot{Q}_{\left(\mathrm{U}_{l}\right)}^{\text {ext,in }}$ - need to be equal to the sum of all heat fluxes leaving an utility $\mathrm{U}_{l}$ towards $\mathrm{E}_{j}$ as well as externally removed heat fluxes $\dot{Q}_{\left(\mathrm{U}_{l}\right)}^{\text {ext,out }}$.

\section{Inequality Constraints for Heat Integration}

The feasibility of the heat integration is assured with inequality constraints. Contrary to the IDEAS approach where feasibility of heat exchangers among different streams needs to be ensured a priori ${ }^{34}$, the lower bound of heat integration i.e. the pinch point is identified with the help of these inequalities. Three different cases for all hot and cold streams are identified, summarized in Tab. .1 and illustrated in Fig. .4. Case I streams can be integrated entirely with utility $\mathrm{U}_{l}$, case II partially and for case III no heat integration is possible: either heat is required at a higher temperature or the temperature of the utilities is too high to be convenient for cooling. For case I, characterized by the possibility of total heat integration, and case II, characterized by the possibility of partial heat integration, internal heat flows $\dot{Q}_{\left(\mathrm{E}_{j}\right)}^{\left(\mathrm{U}_{l}\right)}$ or $\dot{Q}_{\left(\mathrm{U}_{l}\right)}^{\left(\mathrm{E}_{j}\right)}$ are created and added to the energy balance Eq. (5).

To account for the maximum amount of internally transferable heat fluxes of case II streams, 
two subsets of $\mathcal{F}$ that contains all graph edges are introduced as: $\mathcal{F}_{\mathrm{II}}^{\mathrm{UE}}:=\left\{\dot{Q}_{\left(\mathrm{E}_{j}\right)}^{\left(\mathrm{U}_{l}\right)} \in \mathbb{R}_{0}^{+} \mid\right.$ case II satisfied $\}$ and $\mathcal{F}_{\mathrm{II}}^{\mathrm{EU}}:=\left\{\dot{Q}_{\left(\mathrm{U}_{l}\right)}^{\left(\mathrm{E}_{j}\right)} \in \mathbb{R}_{0}^{+} \mid\right.$case II satisfied $\}$. Inequalities for these streams are given by

$$
\begin{aligned}
& 0 \leq \frac{T_{\mathrm{U}_{l}}-T_{\text {cold,in },\left(\mathrm{E}_{j}\right)}-\Delta T_{\text {min }}}{T_{\text {cold }, \text { out },\left(\mathrm{E}_{j}\right)}-T_{\text {cold }, \mathrm{in},\left(\mathrm{E}_{j}\right)}} \varphi_{\left(\mathrm{E}_{j}\right)}^{\mathrm{in}} \dot{\Gamma}_{\left(\mathrm{E}_{j}\right)}-\dot{Q}_{\left(\mathrm{E}_{j}\right)}^{\left(\mathrm{U}_{\mathrm{l}}\right)} \quad \forall \dot{Q}_{\left(\mathrm{E}_{j}\right)}^{\left(\mathrm{U}_{l}\right)} \in \mathcal{F}_{\mathrm{II}}^{\mathrm{UE}} \\
& 0 \leq \frac{T_{\text {hot,in, }\left(\mathrm{E}_{j}\right)}-T_{\mathrm{U}_{l}}-\Delta T_{\mathrm{min}}}{T_{\text {hot,in, }\left(\mathrm{E}_{j}\right)}-T_{\text {hot,out },\left(\mathrm{E}_{j}\right)}} \varphi_{\left(\mathrm{E}_{j}\right)}^{\text {out }} \dot{\Gamma}_{\left(\mathrm{E}_{j}\right)}-\dot{Q}_{\left(\mathrm{U}_{l}\right)}^{\left(\mathrm{E}_{j}\right)} \quad \forall \dot{Q}_{\left(\mathrm{U}_{l}\right)}^{\left(\mathrm{E}_{j}\right)} \in \mathcal{F}_{\mathrm{II}}^{\mathrm{EU}} \quad .
\end{aligned}
$$

Eq. (9a) is used for modeling the maximum heat flux that can be provided from utility $\mathrm{U}_{l}$ to heat the cold elementary process $\mathrm{E}_{j}$, depending on the constant temperature level $T_{\mathrm{U}_{l}}$ of $\mathrm{U}_{l}$. Similarly, Eq. (9b) quantifies the maximum heat that can be transferred between hot elementary process $\mathrm{E}_{j}$ and utility $\mathrm{U}_{l}$.

\section{Formulation of the Flux Optimization Problem}

Within the discretized thermodynamic state space, the process synthesis and heat integration problem is formulated as a constrained flux optimization problem. The mass and energy conservation laws for all node types constitute a linear system of equality constraints. The inequality constraints that result from the heat integration formulation are also linear resulting in a convex feasible region. Therefore, a convex objective function leads to a convex optimization problem and for the special case of a linear objective function to a linear programming problem as stated in Eq. (10).

$$
\begin{array}{rl}
\min _{\mathbf{x}} & f(\mathbf{x})=\mathbf{c}^{\top} \mathbf{x} \\
\text { s.t. } & \mathbf{A}_{\mathrm{eq}} \mathbf{x} \\
& =\mathbf{b}_{\mathrm{eq}} \\
\mathbf{A}_{\mathrm{iq}} \mathbf{x} & \leq \mathbf{b}_{\mathrm{iq}} \\
\mathbf{x}_{\mathrm{lb}} & \leq \mathbf{x} \leq \mathbf{x}_{\mathrm{ub}}
\end{array}
$$


The objective function is denoted with $f$ and $\mathbf{x}=(\dot{\mathbf{N}}, \dot{\boldsymbol{\Gamma}}, \dot{\mathbf{Q}}, \dot{\mathbf{W}})^{\top}$ denotes the vector of all decision variables: internal and external mass fluxes $\dot{\mathbf{N}}$, internal and external heat fluxes $\dot{\mathbf{Q}}$, work fluxes $\dot{\mathbf{W}}$ and PENs $\dot{\boldsymbol{\Gamma}}$. The influence of the decision variables on the objective function is determined by the vector of cost factors $\mathbf{c}^{\top}=\left(\mathbf{c}_{\dot{N}}, \mathbf{c}_{\dot{\Gamma}}, \mathbf{c}_{\dot{Q}}, \mathbf{c}_{\dot{W}}\right)$. The equality constraints, described by the coefficient matrix $\mathbf{A}_{\mathrm{eq}}$ and the vector of right-hand sides $\mathbf{b}_{\mathrm{eq}}$, contain the whole information about the energy and mass balances of EPNs, TSNs and UNs. The incidence matrix $\mathbf{A}_{\mathrm{eq}}$ contains all information on the coupling of nodes and edges of the digraph. The pattern of the equality constraint matrix $\mathbf{A}_{\mathrm{eq}}$ is illustrated in Eq. (11). The equality constraint matrix has the dimension $\mathbf{A} \in \mathbb{R}^{\mathrm{m} \times \mathrm{n}}$ where $\mathrm{m}$ is the total number of nodes and $\mathrm{n}$ the total number of fluxes. It consists of block entries per elementary process node $\mathrm{E}_{j}$, external mass fluxes $\mathbf{A}_{\text {eq }}^{\text {ext }}$ as well as matrix entries for heat fluxes (HI).

$$
\mathbf{A}_{\mathrm{eq}}=\left[\begin{array}{ccccccc}
\mathbf{0} & \mathbf{A}_{\mathrm{eq}}^{\left(\mathrm{E}_{1}\right)} & & & & \mathbf{A}_{\mathrm{eq}}^{\left(\mathrm{E}_{1}\right), \mathrm{HI}} & \mathbf{0} \\
\cdots & & \ldots & & & \ldots & \ldots \\
\mathbf{0} & & & \mathbf{A}_{\mathrm{eq}}^{\left(\mathrm{E}_{j}\right)} & & \mathbf{A}_{\mathrm{eq}}^{\left(\mathrm{E}_{j}\right), \mathrm{HI}} & \mathbf{0} \\
\cdots & & & & \ldots & \ldots & \ldots \\
\mathbf{A}_{\mathrm{eq}}^{\mathrm{ext}} & -\mathbf{A}_{\mathrm{eq}}^{\mathrm{mb},\left(\mathrm{E}_{1}\right)} & \ldots & -\mathbf{A}_{\mathrm{eq}}^{\mathrm{mb},\left(\mathrm{E}_{j}\right)} & \ldots & \mathbf{0} & \mathbf{0} \\
\mathbf{0} & \mathbf{0} & \ldots & \mathbf{0} & \cdots & -\mathbf{A}_{\mathrm{eq}}^{\forall\left(\mathrm{E}_{j}\right), \mathrm{HI}} & \mathbf{A}_{\mathrm{eq}}^{\mathrm{ext}, \mathrm{HI}}
\end{array}\right]
$$

Top entries correspond to conservation laws of process nodes (EPNs) followed by TSNs and at the bottom UNs. Each process node equality constraint matrix contains a PEN scaling variable $\dot{\boldsymbol{\Gamma}}$, internal mass fluxes $\dot{\mathbf{N}}^{\text {(int) }}$ as well as external work fluxes $\dot{\mathbf{W}}^{\text {(ext) }}$. External molar flows to the thermodynamic substance node $\mathrm{M}_{i}, \dot{\mathbf{N}}_{\left(\mathrm{M}_{i}\right)}^{(\text {ext) }}$, are contained in the plant-wide mass balance in the second block from the bottom. Equality constraints for a EPN $\mathrm{E}_{j}$ inside the equality constraint matrix consist of a mass (mb) and energy balance (eb) as shown in 
Eq. (12)

$$
\mathbf{A}_{\mathrm{eq}}^{\left(\mathrm{E}_{j}\right)}=\left[\begin{array}{c}
\mathbf{A}_{\mathrm{eq}}^{\mathrm{mb},\left(\mathrm{E}_{j}\right)} \\
\mathbf{A}_{\mathrm{eq}}^{\mathrm{eb},\left(\mathrm{E}_{j}\right)}
\end{array}\right]
$$

and the order of the variables for each EPN is $\dot{\Gamma}_{\left(\mathrm{E}_{j}\right)}, \dot{N}_{\left(\mathrm{E}_{j}\right)}^{\left(\mathrm{M}_{i}\right)}, \dot{N}_{\left(\mathrm{E}_{j}\right)}^{\left(\mathrm{M}_{i+1}\right)}, \ldots, \dot{W}_{\left(\mathrm{E}_{j}\right)}^{(\mathrm{ext})}$. The secondto-last column of Eq. (11) contains all internal heat fluxes i.e. EPN-UN couplings whereas the last column entries contains the external heat fluxes. Both entries constitute the heat integration formulation highlighted with superscripts HI.

$$
\mathbf{A}_{\mathrm{iq}}=\left[\begin{array}{lllllll}
\mathbf{0} & \mathbf{A}_{\mathrm{iq}}^{\dot{\Gamma}, \mathrm{E}_{1}} & \cdots & \mathbf{A}_{\mathrm{iq}}^{\dot{\Gamma}, \mathrm{E}_{j}} & \cdots & \mathbf{A}_{\mathrm{iq}}^{\mathrm{HI}} & \mathbf{0}
\end{array}\right]
$$

Inequality constraints originating from the heat integration formulation (Eq. (9)) are contained in $\mathbf{A}_{\mathrm{iq}}$ which is shown in Eq. (13): it contains entries at $\dot{\Gamma}$ positions of each EPN and at heat flux positions coupling EPNs with UNs. Right hand sides of both equality and inequality constraints are zero vectors: $\mathbf{b}_{\mathrm{eq}}=\mathbf{0}, \mathbf{b}_{\mathrm{iq}}=\mathbf{0}$.

\section{Case Study: Synthesis of Hydrogen Cyanide}

The superstructure of the simultaneous process synthesis and heat integration case study for the synthesis of HCN is illustrated schematically in a flowsheet in Fig .5 that consists of two parts. The top section (A) comprises both the Degussa and Andrussow process pathways for the synthesis of HCN: mixing of reactants, synthesis reactor which is either a Degussa reactor at variable temperature or an Andrussow reactor, acidic absorption of unreacted $\mathrm{NH}_{3}$, absorption of product $\mathrm{HCN}$ and purification in a distillation column with variable number of stages. Hatched borders around a unit indicate an adiabatic process unit, black arrows represent mass flows and colored arrows (blue \& red) illustrate heat and work demands. The underlying alterantives of the reactor and distillation units are sketched in 
the two insets.

Besides the production route towards $\mathrm{HCN}$ at the top (A), three examples of recycling pathways of hydrogen are illustrated below in section (B) of Fig. .5. Off-gases of the HCN absorber are separated from the byproduct $\mathrm{H}_{2}$ and the remaining gas may be stripped off $\mathrm{CH}_{4}$ in the Degussa, or fully oxidized in the Andrussow process variant. $\mathrm{H}_{2}$ from the purification may undergo one of three recycling options: combustion for energetic integration (I), production of reactant $\mathrm{NH}_{3}$ after a mixing step with nitrogen according to Eq. (14) or production of reactant $\mathrm{CH}_{4}$ (III) according to the Sabatier reaction (Eq. (15)). The byproduct $\mathrm{H}_{2} \mathrm{O}$ from the methanation is separated in a condenser.

$$
\begin{array}{cl}
\mathrm{N}_{2}+3 \mathrm{H}_{2} \rightleftharpoons 2 \mathrm{NH}_{3} & \Delta_{\mathrm{R}} h^{\ominus}=-46 \mathrm{~kJ} / \mathrm{mol} \\
\mathrm{CO}_{2}+4 \mathrm{H}_{2} \rightleftharpoons \mathrm{CH}_{4}+2 \mathrm{H}_{2} \mathrm{O} & \Delta_{\mathrm{R}} h^{\ominus}=-151 \mathrm{~kJ} / \mathrm{mol}
\end{array}
$$

For this contribution a combination of shortcut and rigorous models is used. All process unit models as well as the formulation of the corresponding elementary process nodes is described in the appendix.

The discretized thermodynamic state space is 13-dimensional because it comprises temperature, pressure and 11 chemical species: $\mathrm{H}_{2} \mathrm{O}, \mathrm{CH}_{4}, \mathrm{H}_{2}, \mathrm{~N}_{2}, \mathrm{O}_{2}, \mathrm{NH}_{3}, \mathrm{HCN}, \mathrm{CO}, \mathrm{CO}_{2}, \mathrm{NO}$ and $\mathrm{H}_{2} \mathrm{SO}_{4}$ that is used in the ammonia absorption. With this high dimensionality it is possible but not efficient to identify the globally optimal process through an infinitesimal refining of the thermodynamic grid as was done for process unit design in a previous contribution $^{39}$. Instead, the state space discretization is fine for key process units and coarse for the periphery enabling the fast identification of the most promising process candidates. Fig. .5 illustrates this split into key components and periphery: the main process routes towards HCN are considered in more detail (Fig. .5 A) with two different reactor types and two temperatures for the Degussa reactor as well as four different distillation column designs 
with increasing number of trays. This level of detail is also reflected by the detailed reactor models as described in the appendix. Absorber units are discretized with single units since their operation does not involve neither heating nor cooling duties. The recycling section, however, is described using short-cut reactor models and thus a differentiation among e.g. different reactor conditions is not made. The state space discretization is coarse but enables a good interpretation of results due to the complex interplay of different process units particularly when simultaneous heat integration is considered. The discretization grid of this process synthesis example is derived from process simulations. In order to attain a finer discretization grid or a larger superstructure, one could perform more simulations of all process units - e.g. key units such as reactor and distillation units - or extend the scope to additional unit operations. Although an increase in grid refinement would increase the accuracy of the solution for a defined superstructure, it is the scope of this contribution to provide both a proof-of-concept and to demonstrate that significant process improvements can already be identified using a comparably coarse discretization grid $^{50}$.

\section{Case Study Parameters for the Optimization}

All case study parameters are summarized in Tab. .2. Costs to provide heating duties sat above ambient temperatures are approximated through an estimation of the heat that is usable at this temperature from combustion of natural gas. In this manner, high temperature utilities require more natural gas because not all of the heating value can be used to achieve the utility temperature. Not all commodity prices are listed publically because they often depend on local supplier situations. To maintain comparability among cost values, raw material prices are therefore obtained from Sigma-Aldrich in August 2018 and scaled with the Index Mundi price of $\mathrm{CH}_{4}{ }^{52}$. Water prices are obtained from Statista and $\mathrm{CO}_{2}$ emission prices are taken from August 2018 price of European $\mathrm{CO}_{2}$ emission allowances ${ }^{53,54}$. 


\section{Results \& Discussion}

\section{Objective Functions and System Constraints}

Externally supplied resources i.e. external fluxes into the whole process system that are consumed upon the production of HCN are grouped into raw materials and energy fluxes consisting of heating, cooling and work duties. In addition both variable cost factors are combined in the total variable cost. Raw material optimization is achieved with an objective function for atom economy and the Sheldon E-factor of the process ${ }^{55}$. For this purpose all mass flows that leave the network are multiplied with their respective atom numbers $n_{\text {atom }, i}$ to evaluate the objective function for atom efficiency and with their respective molar masses $\tilde{M}_{i}$ to obtain the E-factor.

Energy optimization is achieved via minimization of total energy inputs and heating utility inputs. Variable cost are minimized through pricing of all raw materials and utility duties according to the data in Tab. .2. Conflicting objectives are identified and analyzed with multiobjective optimization via weighted objective functions The objective functions are summarized in Tab. .3. Atom economy is defined as atoms in the target product(s) divided by the total input of atoms. It is maximized if the number of output atoms is minimized for a constant production amount of HCN. E-factor minimization is the mass equivalent in $\mathrm{kg}_{\text {waste }}$ per $\mathrm{kg}_{\text {product }}$ to the atom economy. Minimization of total duty comprises both in- and outward pointing duty supplies whereas heating minimization comprises solely the externally supplied heating duties which is of particular interest for the selected case study where endoand exothermic reactor options exist. Variable cost minimization prices all external edges with corresponding material and duty cost.

The production capacity of $\mathrm{HCN}$ is set to $200,000 \mathrm{t}_{\mathrm{HCN}} \mathrm{a}^{-1}$. Furthermore, reactants as well as auxiliary materials such as water and air can enter the process but no TSN that represent process intermediates. In addition, all processes must have equal conditions for outward pointing flows in order to enable a fair comparison among all process alternatives. Therefore, 
outward flows must be at reference state and must not contain hazardous substances. For example the off-gases of the Andrussow reactor must undergo a complete oxidation in order to prevent emission of carbon monoxide.

\section{Process Synthesis for the Production of Hydrogen Cyanide without Hydrogen Recycling}

The first goal of process synthesis for the production of HCN is to identify the most resource-efficient reactor-separator combination as shown in Fig. .5 A. Therefore, the recycling of the byproduct $\mathrm{H}_{2}$ is neglected at this stage. Three reactor configurations, a Degussa reactor $R_{(1)}$ operated at $1500 \mathrm{~K}$, a Degussa reactor $\mathrm{R}_{(2)}$ operated at $1300 \mathrm{~K}$ and an Andrussow reactor are considered in combination with four different distillation column designs of 8, 11, 14 and 17 stages. Their reflux ratios are set to achieve a purity of $99.9 \%$ of $\mathrm{HCN}$ in the separator distillate. In order to provide more insights into the results and the impact of the choice of objective function, all possible configurations i.e. 12 optimization scenarios are compared to emphasize the difference in the results.

\section{Identification of Competing Objectives}

Weighted optimization of the five objective functions - atom efficiency, energy, heating, E-factor and variable cost - is illustrated in Fig. .6 where optimal scenarios are always located in the bottom left corner of the diagrams. The legend is illustrated at the top: the color of a data point denotes the reactor node whereas the shape of the data point represents the selected HCN distillation column. Black filled symbols denote results without simultaneous heat integration whereas heat integration is applied in optimization results with colored fillings.

Degussa reactors obtain high yields whereas Andrussow reactors do not require heating. Therefore, atom economy versus energy (Fig. .6 A) as well as atom economy versus heating duties (Fig. .6 B) are both competing objectives. The results thus form a Pareto front that is indicated with the dotted line in both figures. With regard to total duties, both Degussa 
reactors constitute the Pareto front whereas high temperature Degussa and Andrussow reactor make up the Pareto front when heating is examined.

For the twelve possible scenarios under consideration, atom economy and E-factor (Fig. .6 C) yield exactly the same results no matter if simultaneous heat integration is considered or not which is also illustrated in Fig. .7. High atom economies mean less waste and indicate thus good E-factors. The former is a quantification of this effect in terms of moles whereas the E-factor is mass-based. Atom economy and E-factor are therefore not competing objectives. Similar results apply for atom efficiency and variable cost (Fig. .6 D): material flows are the key contributor to variable cost as shown in Fig. .7 D. Therefore, low variable cost also means high atom economy.

\section{Impact of the Reactor Node}

A comparison of the twelve scenarios in more detail is provided in Fig. .7: the results illustrate atom economy, E-factor, utility demands and variable cost for the minimization of variable cost. As mentioned above, processes with high temperature Degussa reactors (red) attain the highest atom economies (Fig. .7 A) of $\eta_{\text {atom }}=12.4 \%$ and lowest E-factors (Fig. .7 B) of $E_{\text {Sheldon }}=3.5$ followed by low temperature Degussa reactors with $\eta_{\text {atom }}=10.9 \%$ and $E_{\text {Sheldon }}=4.2$. Andrussow processes are significantly less raw material efficient with $\eta_{\text {atom }}=8.4 \%$ and $E_{\text {Sheldon }}=7.2$. The results for the E-factor of the Degussa reactors are within the range generally applicable to bulk chemicals whereas the Andrussow process is already in the range of fine chemical production ${ }^{55}$. All these results are not dependent neither on the type of the distillation column nor on heat integration.

Comparison of the duties involved in each scenario (Fig. .7 C) shows that low temperature Degussa processes (blue) have the lowest total duty consumption both with and without heat integration. Therefore, they constitute the low-duty-edge of the Pareto front in (Fig. .6 A) with the high temperature Degussa reactors at the high-atom-economy edge (red). With 
respect to heating, the Andrussow processes (yellow) are optimal due to the exothermal reactor nodes. The general idea of operating the Degussa reactor at lower temperature is to reduce heating cost at the price of a decrease in yield: the reduction in atom economy, however, is not compensated by lower heating duties. Processes that employ low temperature Degussa reactors thus lie within the Pareto region in Fig. .6 B. Consequently, if one desires to operate an atom economic and energy efficient process, one has to choose either the high temperature Degussa, the low temperature Degussa reactor or a mixture of both. If - on the other hand - one wants to minimize heating instead of total duties one has to weigh between high temperature Degussa and Andrussow reactors.

Including simultaneous heat integration in the process synthesis reduces variable cost for all process possibilities (Fig. .7 D): around $2.5 \%$ for both Degussa reactor types and roughly $4.5 \%$ for the Andrussow reactor even though all have a similar reduction in total duties as shown in Fig. .7 C. The reason for the enhanced reduction of variable costs for the Andrussow process are the temperature levels: heat integration aside, the heating demand of Degussa reactors is at high temperatures whereas the Andrussow reactor requires less costly cooling duties. In total, heat integration does reduce variable cost but key contributor are mass flow cost which is why different recycling pathways are considered below.

\section{Impact of the Distillation Column Node}

Prior to discussion of the recycling potentials, the impact of the distillation column on the overall process performance is briefly discussed. Comparing the processes without simultaneous heat integration (black-filled) in Fig. .6 A and B it is evident that the column with the least number of stages requires the highest amount of duties and vice versa for the column with the highest number of stages (17 stages). Process design without taking simultaneous heat integration into account would clearly identify the column with 17 stages as the most resource-efficient process. In a subsequent pinch analysis one would find out that 
its heating and cooling duties can be fully integrated using the internal heat flows within the overall process.

Considering heat integration simultaneously to the process synthesis, however, reveals that no difference in the process performance among all four column designs exist in terms of neither heating nor total energy duties. This is due to the fact, that all duty requirements of the columns can be integrated with internal heat flows of the processes for all column designs and reactor designs except for the column with the minimum number of eight theoretical stages in combination with the low temperature Degussa reactor which is also visible in Fig. 7 C: the white bar of scenario 8 is higher than its benchmark scenarios 5,6 and 7. Consequently, resource-efficient process design without access to simultaneous process synthesis and heat integration identifies the process with the distillation column with 17 stages to be optimal while all distillation columns within the process under consideration are equally resource-efficient. The approach of simultaneous process synthesis and heat integration thus enables to identify process pathways that are structurally different and cannot be identified using a conventional consecutive approach of mass flow optimization and subsequent heat integration.

\section{Process Synthesis for the Production of Hydrogen Cyanide Including Hydrogen Recycling}

Within this section the room for improvement with respect to the five target objectives through consideration of the three recycling pathways shown in Fig. .5 B is illustrated. The results are structured into three parts: first, the recycling pathways are compared with regard to their effect on the objective functions. Subsequently, Pareto optimal scenarios are identified through multi-objective optimization and in the last part the Pareto optimal results are analyzed in more detail. 


\section{Comparison of Recycling Pathways}

Fig. 8 demonstrates the impact of heat integration and the three recycling pathways on the process performance for the three reactor types. As shown above, the selection of the distillation column within this specific process context is of minor importance and thus not discussed in detail. Background colors in Fig. .8 correspond to three reactor nodes that are available, and the five bars for each reactor node type correspond to the standard process without heat integration, with heat integration, with energetic $\mathrm{H}_{2}$ recycling through combustion, with production of the reactant $\mathrm{NH}_{3}$ and with production of the reactant $\mathrm{CH}_{4}$. Heating duties of the Andrussow process are effectively reduced to zero by heat integration (indicated with 0 ). The combustion of its byproduct $\mathrm{H}_{2}$ provides thus no benefits for the process and is not included in the diagram (indicated with $\mathrm{X}$ ).

It is common practice in industry to recycle the byproduct $\mathrm{H}_{2}$ energetically in the synthesis furnaces of Degussa reactors. Fig. . $8 \mathrm{D}$ confirms that combustion of $\mathrm{H}_{2}$ reduces heating duties to $13 \%$ for high and completely to $0 \%$ for low temperature Degussa reactors. However, at the same time, cooling and work duties (Fig. .8 C) increase due to the assumption of a clean combustion of pure $\mathrm{H}_{2}$. Overall, this pathway deteriorates variable cost by $20 \%$ and $38 \%$ for the reactor nodes $R_{(1)}$ and $R_{(2)}$. The effect is larger for the low temperature Degussa reactor because its reactor outlet stream contains considerably less $\mathrm{H}_{2}$. Another negative side-effect of the combustion of $\mathrm{H}_{2}$ is the decrease in atom economy (Fig. .8 A) by $39 \%$ and $38 \%$ and an increase in E-factors (Fig. .8 B) by $256 \%$ and $233 \%$ due to air flow that is required for combustion leading to large waste streams. The reason why this process alternative is often selected in industrial processes is that the purification step is omitted leading to a mixed combustion of non-reacted $\mathrm{CH}_{4}$ and fuel gas streams in the furnace. In this manner, the total variable cost may be reduced by a few percent. Two drawbacks of the combustion of $\mathrm{H}_{2}$ remain, however: the drop in atom economy and increase in waste streams as well as an increase in separation and cooling duties due to the definition of boundary conditions. 
In addition, heating cost account for a minor contribution of the total variable cost as was shown in Fig. .7 D.

The second recycling alternative is the production of $\mathrm{NH}_{3}$ from the side product $\mathrm{H}_{2}$ to improve atom economy and reduce waste. Fig. $8 \mathrm{~A}$ shows improvements in atom economy by $19 \%, 23 \%$ and $9 \%$ for the base processes of the three reactor nodes $R_{(1)}, R_{(2)}$ and $R_{(3)}$. The reduction mass amounts is smaller (Fig. .8 B) accounting for $4 \%, 9 \%$ and $1.5 \%$ because of the low molar mass of $\mathrm{H}_{2}$. The production of $\mathrm{NH}_{3}$ is exothermal requiring additional cooling duties (Eq. (14)) but the temperature levels are not sufficiently high to provide heat to the endothermal Degussa reactors. Therefore, no improvement is attained in terms of heating duties when $\mathrm{NH}_{3}$ is produced. The most significant effect of the on-site production of $\mathrm{NH}_{3}$ is the decline in total variable cost. Reactant cost and in particular the cost of $\mathrm{NH}_{3}$ are the key drivers of variable cost. Production of $\mathrm{NH}_{3}$ leads to a decrease in $67 \%$ and $51 \%$ for $R_{(1)}$ and $R_{(2)}$. On the other hand, variable cost of the Andrussow process are increased by $6 \%$ if $\mathrm{NH}_{3}$ is produced. The reason for this range from strong decrease to an increase in variable cost originates from the different purities of $\mathrm{H}_{2}$ in the reactor outlet streams of the base case processes and subsequent requirements for purification prior to production of $\mathrm{NH}_{3}$ : whereas the outlet stream of $\mathrm{R}_{(1)}$ is rich in $\mathrm{H}_{2}$, the outlet stream of $\mathrm{R}_{(2)}$ contains less $\mathrm{H}_{2}$ and the outlet stream of $\mathrm{R}_{(3)}$ has a hydrogen outlet molar fraction of $x_{\mathrm{H}_{2}}=12 \%$. Therefore, cost for purification of $\mathrm{H}_{2}$ are low for $\mathrm{R}_{(1)}$ and higher for $\mathrm{R}_{(2)}$ and $\mathrm{R}_{(3)}$. In total, production of $\mathrm{NH}_{3}$ has strong benefits for processes with Degussa but not with Andrussow reactors. The third recycling pathway is the production of $\mathrm{CH}_{4}$ via the Sabatier reaction where an additional benefit exists in the consumption of the greenhouse gas $\mathrm{CO}_{2}$. Atom economies (Fig. $8 \mathrm{~A}$ ) are increased by $40 \%$ for both $\mathrm{R}_{(1)}$ and $\mathrm{R}_{(2)}$ and $9 \%$ for $\mathrm{R}_{(3)}$. At first sight it is surprising that the increase in atom economy for the Degussa reactors is higher than for production of $\mathrm{NH}_{3}$ because comparison of the reaction equations (Eq. (14), Eq. (15)) shows that for equal amounts of $\mathrm{H}_{2}$ to be recycled, $100 \%$ of the $\mathrm{H}_{2}$ is converted to reactants for 
the former and a mere $50 \%$ of $\mathrm{H}_{2}$ is converted to reactants in the Sabatier reaction. In the context of the entire process, however, also the side product $\mathrm{H}_{2} \mathrm{O}$ from the Sabatier reaction can be used for the absorption of $\mathrm{NH}_{3}$ and $\mathrm{HCN}$ in the downstream processing and thus the atom efficiency saving potentials of both recycling pathways are equally high. The reason why the improvements in atom economy for $\mathrm{CH}_{4}$ production are larger compared to $\mathrm{NH}_{3}$ for $R_{(1)}$ and $R_{(2)}$, consists of the fact that more $\mathrm{H}_{2}$ is available than can be used as $\mathrm{NH}_{3}$ in the reactor whereas the full amount of $\mathrm{H}_{2}$ can be exploited if both $\mathrm{CH}_{4}$ and $\mathrm{H}_{2} \mathrm{O}$ are used. The process with the Andrussow reactor node $\mathrm{R}_{(3)}$ does not show this behavior because $\mathrm{H}_{2}$ is not available in sufficient amounts to cover the consumption of $\mathrm{NH}_{3}$ in the reactor: therefore, both recycling pathways exhibit the same value in atom efficiency.

As before, heating duties are not affected (Fig. $.8 \mathrm{D}$ ) and total duty increase if $\mathrm{CH}_{4}$ is produced on-site. The increase in duties is stronger compared to production of $\mathrm{NH}_{3}$ because the reaction enthalpy of the Sabatier reaction is considerably larger requiring more cooling. Contrary to the gains in atom efficiency for production of $\mathrm{CH}_{4}$, a decrease in total variable cost for all reactor nodes is reported: $26 \% \mathrm{R}_{(1)}, 48 \%$ for $\mathrm{R}_{(2)}$ and $58 \%$ for $\mathrm{R}_{(3)}$. The reason is, that the separation cost of $\mathrm{H}_{2}$ from the off-gas stream are more expensive than the procurement of the reactant $\mathrm{CH}_{4}$ which is available at low prices on the world market. The increase in variable cost is more pronounced for $R_{(2)}$ and $R_{(3)}$ because the separation cost in the $\mathrm{H}_{2}$ separator are higher for those processes.

In summary, globally optimal scenarios include either production of $\mathrm{CH}_{4}$ to attain high atom efficiencies or production of $\mathrm{NH}_{3}$ for high atom efficiencies and low total variable cost.

\section{Pareto-Optimal Process Pathways}

Having discussed the impact of the three recycling pathways on the objective functions, it is the focus of this section to identify the overall most resource-efficient process. The objectives atom efficiency and total variable cost are weighted with utility objective functions 
in a multi-objective optimization and the results are shown in Fig. .9 where the illustrated processes are limited to process candidates that lie at the edge of the Pareto fronts. As in Fig. .6, colors represent the type of reactor node whereas an additional color - turquoise - identifies processes that employ a combination of the reactor nodes. Shapes correspond to recycling pathways: $\mathrm{H}_{2}$ combustion, $\mathrm{NH}_{3}$ production, $\mathrm{CH}_{4}$ production, any combination thereof and no recycling at all. Results with and without heat integration are highlighted color- and gray-filled symbols and the resulting two Pareto fronts are indicated with a dashed line (no heat integration) and a dotted line (heat integration).

The results for atom efficiency versus total duty requirement (Fig. .9 A) confirm the observations above: recycling leads to higher total duty requirements and thus no recycling is at the total duty optimal range whereas the production of $\mathrm{CH}_{4}$ for the reactor node $\mathrm{R}_{(1)}$ leads to the best atom economy which is better than for the production of $\mathrm{NH}_{3}$. Heat integration leads to a shift of all scenarios to lower duty requirements. An additional process design denoted with $\alpha$ is identified which has a lower total duty at similar minimal atom efficiency. Results for atom efficiency versus heating are shown in Fig. $.9 \mathrm{~B}$ which correspond to a horizontal shift of the results of A: Andrussow reactor nodes require no heating and their atom economy is improved through either $\mathrm{NH}_{3}$ or $\mathrm{CH}_{4}$ production to the same extent as was mentioned above and high temperature Degussa and production of $\mathrm{CH}_{4}$ remain at the optimal atom efficient corner where also the $\alpha$ design is located because its requirements for heating duty equal the $\mathrm{R}_{(1)}-\mathrm{CH}_{4}$ combination. Interestingly, another structurally new process is identified due to the simultaneous heat and mass optimization which would not appear in a two-step consecutive approach: The low temperature Degussa's heat duty requirements are effectively reduced to zero through combustion of its side product $\mathrm{H}_{2}$.

The calculation is repeated for variable cost versus energy (Fig. .9 C) which is similar to atom efficiency versus energy (Fig. .9 A): no recycling for the two Degussa-type reactors for minimal energy requirements but now the production of $\mathrm{NH}_{3}$ in combination with $\mathrm{R}_{(1)}$ 
at the minimal variable cost as was shown in Fig. 8 E. Replacing total duty with heating duty in Fig. .8 D is similar to B and C: Andrussow designs replace low temperature Degussa and $\mathrm{NH}_{3}$ production replaces the production of $\mathrm{CH}_{4}$. In addition to these expected results a second new process denoted with $\beta$ is identified: it has equally low variable cost like the $\mathrm{R}_{(1)}-\mathrm{NH}_{3}$ combination at significantly lower heating duties. The novel designs $\alpha$ and $\beta$ are discussed in more detail in the following section.

\section{Analysis of Best Designs}

The flowsheets of the two novel designs $-\alpha$ and $\beta$ are illustrated in Fig. .10 A and B. The $\alpha$ process design attains the same globally optimal atom efficiency as the Degussa $\mathrm{R}_{(1)}$ reactor in combination with the production of $\mathrm{CH}_{4}$ through a combination of the same reactor node with both production of $\mathrm{NH}_{3}$ and $\mathrm{CH}_{4}$. As both recycling processes have equal resource-saving potential the application of more $\mathrm{NH}_{3}$ production results in lower total duty requirements due to lower reaction enthalpy of the $\mathrm{NH}_{3}$ synthesis reaction.

The $\beta$ design has similarly low variable cost as the $\mathrm{R}_{(1)}-\mathrm{NH}_{3}$ process at lower heating duty requirements. This is achieved through a combination of the benefits of both reactor concepts: the Degussa and the Andrussow process: the $\mathrm{H}_{2}$ outlet of the high temperature Degussa reactor is exploited for the maximum production of $\mathrm{NH}_{3}$ while zero-heating-duty Andrussow reactor is applied to reduce heating requirements. Overall duty is with $40.6 \mathrm{MJ} / \mathrm{t}_{\mathrm{HCN}} 10 \%$ below the $\mathrm{R}_{(1)}-\mathrm{NH}_{3}$ combination.

Both new designs are compared in more detail in Fig. .10 C, D, E and F with respect to atom efficiencies, E-factor, duty requirements and variable cost. Both design candidates represent resource-efficient designs because they have high atom efficiencies and low total variable cost. Their heating and total duty requirements are not among the top process candidates such as a pure Andrussow in the case of minimal heating cost but the impact of raw material efficiency is emphasized over energy efficiency due to its larger contribution to total variable 
cost for the case study under consideration.

The Degussa reactor $\mathrm{R}_{(1)}$ appears in both scenarios $\alpha$ and $\beta$ and is thus considered a base case for comparison with the two novel designs. The results of the objectives relative to this base case are presented in Tab. .4.

The direct comparison of the results show that heat integration does reduce utility requirements significantly but has a minor effect on total variable cost whereas recycling of $\mathrm{H}_{2}$ to produce valuable $\mathrm{NH}_{3}$ may reduce the total variable cost by 55-68\% despite higher total duty requirements. Depending on the specific site requirements and regulations either the more reactant-efficient $(\alpha)$ or the more heating efficient $(\beta)$ process design is of interest.

It has to be kept in mind, that a significantly larger amount of process units is required for the process $\beta$ due to the parallel operation of both the Andrussow and the Degussa reactors and related downstream process units. It was the scope to emphasize the most resource-efficient production processes from a technological perspective. In practice various aspects may lead to dramatically different results: $\mathrm{HCN}$ and $\mathrm{NH}_{3}$ are often traded and exchanged locally resulting in strongly different cost scenarios; fixed cost, maintenance, insurance and other regulatory aspects may lead to strongly different results as well. Nonetheless, the results that are presented here demonstrate the potential of the FluxMax approach of identifying and optimizing a priori non-intuitive process structures.

\section{Conclusion}

The FluxMax Approach, that enables a simultaneous heat and mass flux optimization through a discretization of the thermodynamic state space is introduced and demonstrated using the process synthesis for production of $\mathrm{HCN}$ as a case study. Nonlinearities that are involved in each process unit model are effectively decoupled from the optimization problem leading to a convex feasible region where the heat integration problem is formulated as a series of linear inequality constraints. By use of linear objective functions, globally optimal 
- within the discretized network - solutions are identified for the case study that reveal that there is not a single but multiple optimal process pathways: It does not suffice to consider neither energy efficiency nor raw material efficiency in an isolated fashion. A comprehensive consideration of resource efficiency incorporating energy, raw material and financial resources as a whole is required, instead, as illustrated by the chosen case study where mutual dependencies among objectives and competing objectives are significant. Five objective functions are identified as atom efficiency and E-factor for raw material efficiency, heating and total duty to assess the energetic performance and total variable cost to provide a comparative framework of the two. Using multi-objective optimization, competing objectives are systematically analyzed and the identification of the most resource-optimal solutions is achieved. By means of the case study of HCN production, it is demonstrated that the FluxMax approach is able to identify structurally novel processes that are not identifiable using a sequential approach of process synthesis and subsequent heat integration: Process steps in the case study where heat integration is a crucial aspect such as the selection of the distillation column and energetic recycling of $\mathrm{H}_{2}$ are correctly assessed and integrated with the simultaneous process synthesis and heat integration approach. The case study demonstrates that no process design is superior in all five objectives but resource efficiency contributes significantly more to variable cost than utility duties. Consequently, the most resource-efficient process which is the high temperature Degussa process is selected as a benchmark scenario. Two novel process designs lead to improvements in atom efficiency of $39.5 \%$ and variable cost reduction of $67.6 \%$, however, at the price of an increase in overall utility duties between $28.7 \%$ and $48.4 \%$.

The selected case study illustrates that a simultaneous consideration of material and energy fluxes is essential for the identification of overall resource-optimal solutions. The proposed FluxMax Approach provides therefore a substantial advantage over sequential methods wherein single process units are optimized first followed by a subsequent energy integration 
study through a pinch analysis. The FluxMax approach has the advantage that heat integration is achieved with a limited overhead while maintaining a convex feasible region. The novel approach identifies the globally optimal solution if convex objective functions are selected. However, it identifies the solution only within the selected discretized state space. A limited number of discretization points was chosen for the illustrative power of the case study in this contribution and further grid refinement to identify the true global process optimum within a defined search space of feasible unit operations is subject to ongoing research. Applications are possible ranging from the identification of a global optimum through grid refinement to retrofitting of existing plants and equipment with a limited number of grid points. Depending on the application type care must therefore be taken in selecting an adequate grid of thermodynamic state nodes. Objective functions are readily expandable to fix cost through the formulation of the network flow problem using process extent variables. Due to its length-scale independent applicability, the proposed FluxMax approach might become also a helpful tool in site planning and retrofitting of existing plants in the future.

\section{Acknowledgements}

The author Georg Liesche is also affiliated to the International Max Planck Research School (IMPRS) for Advanced Methods in Process Systems Engineering (Magdeburg).

\section{Nomenclature}

$\chi_{\left(\mathrm{E}_{j}\right)}^{\left(\mathrm{M}_{i}\right)}$ stoichiometric coefficient of $\mathrm{M}_{i}$ in $\mathrm{E}_{j}$

$\Delta_{R} h^{\ominus}$ reaction enthalpy at standard conditions / $\mathrm{kJ} / \mathrm{mol}$

$\Delta_{\mathrm{M}} g$ molar Gibbs enthalpy of mixing / kJ/mol

$\dot{\Gamma} \quad$ variable of a process extent number $/ \mathrm{mol} / \mathrm{s}$ 
$\dot{\xi} \quad$ extent of reaction $\mathrm{mol} / \mathrm{s}$

$\dot{N}_{\left(\mathrm{E}_{j}\right)}^{\left(\mathrm{M}_{i}\right)}$ molar flux linking TSN $\mathrm{M}_{i}$ with $\mathrm{EPN} \mathrm{E} j / \mathrm{mol} / \mathrm{s}$

$\dot{Q}_{\left(\mathrm{E}_{j}\right)}^{\left(\mathrm{U}_{l}\right)}$ heat flux from UN $\mathrm{U}_{l}$ towards EPN $\mathrm{E}_{j} / \mathrm{kW}$

$\dot{W}_{\left(\mathrm{E}_{j}\right)}^{(\mathrm{ext})}$ external work flux to process node $\mathrm{E}_{j} / \mathrm{kW}$

$\eta \quad$ separation efficiency for gas separation / -

$\eta_{\left(\mathrm{E}_{j}\right)}^{\text {in }}$ efficiency factor of work consuming EPN $\mathrm{E}_{j}$

$\mathbf{A}_{\text {eq }}$ matrix of equality constraints

$\mathbf{A}_{\text {iq }}$ matrix of inequality constraints

$\mathbf{b}_{\mathrm{eq}} \quad$ right hand side of the equality constraints

$\mathbf{b}_{\text {iq }} \quad$ right hand side of the inequality constraints

$\mathbf{x} \quad$ solution vector of the LP

$\mathcal{E} \quad$ set of all elementary process nodes

$\mathcal{F} \quad$ set of all molar, heat and work flux edges

$\mathcal{M}$ set of all thermodynamic substance nodes

$\mathcal{U} \quad$ set of all utility nodes

$\omega \quad$ molar work duty of a EPN / kJ/mol

$\tilde{M}_{i} \quad$ molar mass of TSN $i / \mathrm{kg} / \mathrm{mol}$

$\varphi \quad$ molar heat duty of a EPN / kJ/mol

e entrainer-to-feed ratio 
$f \quad$ objective function

$n_{\text {atom }, i}$ number of atoms of TSN $i / \mathrm{mol}^{-1}$

$p \quad$ pressure / $\mathrm{Pa}$

$p_{\dot{W}^{\text {ext }}} \quad$ cost of work duty / EUR/kJ

$T \quad$ temperature / $\mathrm{K}$

$x \quad$ molar fraction / -

$\mathrm{A}_{j} \quad$ absorber process node $j$

$\mathrm{D}_{j} \quad$ temperature state changer process node $j$

$\mathrm{E}_{j} \quad$ symbol of an elementary process node

ENRTL-RK electrolyte non-random-two-liquid model combined with the Redlich-Kwong equation of state

EPF elementary process functions

EPN elementary process nodes

FMA FluxMax Approach

$\mathrm{G}_{j} \quad$ generic process node $j$

HEN heat exchanger network

$\mathrm{L}_{j} \quad$ mixing process node $j$

LP linear programming

$\mathrm{M}_{i} \quad$ symbol of a thermodynamic substance node 
MILP mixed inter linear programming

MINLP mixed integer nonlinear programming

PEN process extent number

PMB partial mass balance

$\mathrm{R}_{j} \quad$ reactor process node $j$

$\mathrm{S}_{k} \quad$ symbol of a work utility node

TSN thermodynamic substance nodes

$\mathrm{U}_{l} \quad$ symbol of a utility node

UN utility nodes

WHEN work and heat exchanger networks

WUN work utility node

\section{Literature Cited}

[1] Wackernagel M, Browne S. Earth Overshoot Day. https://www.overshootday.org/ Accessed December 10, 2018.

[2] Bosseboeuf D. Energy Efficiency Trends and Policies In Industry - An Analysis Based on the ODYSSEE and MURE Databases. Grenoble: Enerdata. 2015.

[3] Freund H, Sundmacher K. Process Intensification, 4. Plant Level. In: Ullmann's Encyclopedia of Industrial Chemistry. Weinheim, Germany: Wiley-VCH Verlag. 2011;55:130. 
[4] Baldea M. A pinch-like targeting framework for systematic thermal process intensification. AIChE Journal. 2018;64(3):877-885.

[5] Linnhoff B, Flower JR. Synthesis of heat exchanger networks: I. Systematic generation of energy optimal networks. AIChE Journal. 1978;24(4):633-642.

[6] Friedler F. Process integration, modelling and optimisation for energy saving and pollution reduction. Applied Thermal Engineering. 2010;30(16):2270-2280.

[7] Sternberg A, Bardow A. Power-to-What? - Environmental assessment of energy storage systems. Energy \&6 Environmental Science. 2015;8(2):389-400.

[8] Otto A, Grube T, Schiebahn S, Stolten D. Closing the loop: captured $\mathrm{CO}_{2}$ as a feedstock in the chemical industry. Energy \& Environmental Science. 2015;8(11):3283-3297.

[9] Deutz S, Bongartz D, Heuser B, Kätelhön A, Schulze Langenhorst L, Omari A, Walters M, Klankermayer J, Leitner W, Mitsos A, Pischinger S, Bardow A. Cleaner production of cleaner fuels: wind-to-wheel - environmental assessment of $\mathrm{CO}_{2}$-based oxymethylene ether as a drop-in fuel. Energy \& Environmental Science. 2018;11(2):331-343.

[10] Roh K, Frauzem R, Nguyen TB, Gani R, Lee JH. A methodology for the sustainable design and implementation strategy of $\mathrm{CO}_{2}$ utilization processes. Computers $\&$ Chemical Engineering. 2016;91:407-421.

[11] Papoulias SA, Grossmann IE. A structural optimization approach in process synthesisIII. Computers \&6 Chemical Engineering. 1983;7(6):723-734.

[12] Hartono B, Heidebrecht P, Sundmacher K. Combined branch and bound method and exergy analysis for energy system design. Industrial 8 Engineering Chemistry Research. 2012;51(44):14428-14437. 
[13] Voll A, Marquardt W. Reaction network flux analysis: Optimization-based evaluation of reaction pathways for biorenewables processing. AIChE Journal. 2012;58(6):1788-1801.

[14] Martín M, Grossmann IE. Energy optimization of bioethanol production via gasification of switchgrass. AIChE Journal. 2011;57(12):3408-3428.

[15] Kim J, Sen SM, Maravelias CT. An optimization-based assessment framework for biomass-to-fuel conversion strategies. Energy $\&$ Environmental Science. 2013;6(4):1093.

[16] Kokossis AC, Tsakalova M, Pyrgakis K. Design of integrated biorefineries. Computers \& Chemical Engineering. 2015;81:40-56.

[17] Gençer E, Agrawal R. Synthesis of efficient solar thermal power cycles for baseload power supply. Energy Conversion and Management. 2017;133:486-497.

[18] Gençer E, Agrawal R. Toward supplying food, energy, and water demand: Integrated solar desalination process synthesis with power and hydrogen coproduction. Resources, Conservation and Recycling. 2018;133:331-342.

[19] Ulonska K, Skiborowski M, Mitsos A, Viell J. Early-stage evaluation of biorefinery processing pathways using process network flux analysis. AIChE Journal. 2016;62(9):30963108.

[20] Fu C, Vikse M, Gundersen T. Challenges in work and heat integration. Chemical Engineering Transactions. 2017;61:601-606.

[21] Fu C, Vikse M, Gundersen T. Work and heat integration: An emerging research area. Energy. 2018;158:796-806.

[22] Huang K, Karimi IA. Work-heat exchanger network synthesis (WHENS). Energy. 2016; 113:1006-1017. 
[23] Yu H, Eason J, Biegler LT, Feng X. Simultaneous heat integration and techno-economic optimization of Organic Rankine Cycle (ORC) for multiple waste heat stream recovery. Energy. 2017;119:322-333.

[24] Kermani M, Wallerand AS, Kantor ID, Maréchal F. Generic superstructure synthesis of organic Rankine cycles for waste heat recovery in industrial processes. Applied Energy. 2018;212:1203-1225.

[25] Papoulias SA, Grossmann IE. A structural optimization approach in process synthesisII. Computers \& Chemical Engineering. 1983;7(6):707-721.

[26] Duran MA, Grossmann IE. Simultaneous optimization and heat integration of chemical processes. AIChE Journal. 1986;32(1):123-138.

[27] Colberg RD, Morari M. Area and capital cost targets for heat exchanger network synthesis with constrained matches and unequal heat transfer coefficient. Computers $\&$ Chemical Engineering. 1990;14(1):1-22.

[28] Yee TF, Grossmann IE, Kravanja Z. Simultaneous optimization models for heat integration - III. Process and heat exchanger network optimization. Computers $\&$ Chemical Engineering. 1990;14(11):1185-1200.

[29] Dowling AW, Biegler LT. A framework for efficient large scale equation-oriented flowsheet optimization. Computers \& Chemical Engineering. 2015;72:3-20.

[30] Huang B, Li Y, Gao R, Zuo Y, Dai Z, Wang F. Simultaneous optimization and heat integration of the coal-to-SNG process with a branched heat recovery steam cycle. Computers $\& 3$ Chemical Engineering. 2018;117:117-128.

[31] Kong L, Wu Y, Maravelias CT. Simultaneous Utility and Heat Exchanger Area Tar- 
geting for Integrated Process Synthesis and Heat Integration. Industrial $\&$ Engineering Chemistry Research. 2017;56(41):11847-11859.

[32] Bertran MO, Frauzem R, Sanchez-Arcilla AS, Zhang L, Woodley JM, Gani R. A generic methodology for processing route synthesis and design based on superstructure optimization. Computers \& Chemical Engineering. 2017;106:892-910.

[33] Martelli E, Elsido C, Mian A, Marechal F. MINLP model and two-stage algorithm for the simultaneous synthesis of heat exchanger networks, utility systems and heat recovery cycles. Computers \& Chemical Engineering. 2017;106:663-689.

[34] Pichardo P, Manousiouthakis VI. Infinite DimEnsionAl State-space as a systematic process intensification tool: Energetic intensification of hydrogen production. Chemical Engineering Research and Design. 2017;120:372-395.

[35] Friedler F, Tarján K, Huang YW, Fan LT. Graph-theoretic approaches to process synthesis: Axioms and theorems. Chemical Engineering Science. 1992;47:1973-1988.

[36] Nagy AB, Adonyi R, Halasz L, Friedler F, Fan LT. Integrated synthesis of process and heat exchanger networks: algorithmic approach. Applied Thermal Engineering. 2001; 21(13-14):1407-1427.

[37] Schack D, Rihko-Struckmann L, Sundmacher K. Structure optimization of powerto-chemicals (P2C) networks by linear programming for the economic utilization of renewable surplus energy. In: 26th European Symposium on Computer Aided Process Engineering, edited by Kravanja Z, Miloš Bogataj. Elsevier. 2016;38:1551-1556. http://www.sciencedirect.com/science/article/pii/B9780444634283502630

[38] Schack D, Rihko-Struckmann L, Sundmacher K. Linear programming approach for structure optimization of renewable-to-chemicals (R2Chem) production networks. Industrial \&3 Engineering Chemistry Research. 2018;57(30):9889-9902. 
[39] Liesche GS, Schack D, Rätze K, Sundmacher K. Thermodynamic network flow approach for chemical process synthesis. In: 28th European Symposium on Computer Aided Process Engineering, edited by Friedl A, Klemeš J, Stefan Radl, Varbanov P, Wallek T. Elsevier. 2018;43:881-886. http://www.sciencedirect.com/science/article/pii/ B9780444642356501546

[40] Gail E, Gos S, Kulzer R, Lorösch J, Rubo A, Sauer M, Kellens R, Reddy J, Steier N, Hasenpusch W. Cyano Compounds, Inorganic. In: Ullmann's Encyclopedia of Industrial Chemistry. Weinheim, Germany: Wiley-VCH Verlag. 2011;11:673-710.

[41] Endter F. Die technische Synthese von Cyanwasserstoff aus Methan und Ammoniak ohne Zusatz von Sauerstoff. Chemie Ingenieur Technik - CIT. 1958;30(5):305-310.

[42] Koberstein E. Model reactor studies of the hydrogen cyanide synthesis from methane and ammonia. Industrial $\mathscr{G}$ Engineering Chemistry Process Design and Development. 1973;12(4):444-448.

[43] Andrussow L. Über die katalytische Oxydation von Ammoniak-Methan-Gemischen zu Blausäure. Angewandte Chemie. 1935;48(37):593-604.

[44] Kautter CT, Leitenberger W. Großtechnische Herstellung von Cyanwasserstoff nach Andrussow. Chemie Ingenieur Technik. 1953;25(12):697-701.

[45] Waletzko N, Schmidt LD. Modeling catalytic gauze reactors: HCN synthesis. AIChE Journal. 1988;34(7):1146-1156.

[46] Freund H, Sundmacher K. Towards a methodology for the systematic analysis and design of efficient chemical processes. Chemical Engineering and Processing: Process Intensification. 2008;47(12):2051-2060. 
[47] Peschel A, Jörke A, Sundmacher K, Freund H. Optimal reaction concept and plant wide optimization of the ethylene oxide process. Chemical Engineering Journal. 2012; 207-208:656-674.

[48] Kaiser NM, Flassig RJ, Sundmacher K. Reactor-network synthesis via flux profile analysis. Chemical Engineering Journal. 2018;335:1018-1030.

[49] Wilson S, Manousiouthakis V. IDEAS approach to process network synthesis: Application to multicomponent MEN. AIChE Journal. 2000;46(12):2408-2416.

[50] da Cruz FE, Manousiouthakis VI. Process intensification of reactive separator networks through the IDEAS conceptual framework. Computers \&5 Chemical Engineering. 2017; 105:39-55.

[51] Cabezas H, Argoti A, Friedler F, Mizsey P, Pimentel J. Design and engineering of sustainable process systems and supply chains by the P-graph framework. Environmental Progress E Sustainable Energy. 2018;37(2):624-636.

[52] Barrientos M, Soria C. Index Mundi - Commodity Prices Indices. https://www. indexmundi.com Accessed December 10, 2018.

[53] Statista Ltd. Statista - Average US Industrial Water and Sewage Costs. https://www. statista.com/ Accessed December 10, 2018.

[54] finanzennet GmbH. $\mathrm{CO}_{2}$ European Emission Allowances. https://www .finanzen.net/ rohstoffe/co2-emissionsrechte Accessed December 10, 2018.

[55] Sheldon RA. Atom efficiency and catalysis in organic synthesis. Pure and Applied Chemistry. 2000;72(7):1233-1246. 
[56] Liesche G, Sundmacher K. Identification of key transport phenomena in hightemperature reactors: flow and heat transfer characteristics. Industrial \& Engineering Chemistry Research. 2018;57(46):15884-15897.

[57] Hasenberg D, Schmidt LD. HCN synthesis from $\mathrm{CH}_{4}, \mathrm{NH}_{3}$ and $\mathrm{O}_{2}$ on clean Pt*. Journal of Catalysis. 1987;104:441-453.

[58] Perry RH, Chilton CH. Chemical Engineer's Handbook. New York: McGraw Hill, 6th ed. 1984 .

\section{Elementary Process Node Modeling in the Case Study Example}

Based on the general conservation laws that were formulated above characteristic parameters of an EPN are identified as process-related stoichiometric coefficients $\chi_{\left(\mathrm{E}_{j}\right)}^{\left(\mathrm{M}_{i}\right)}$ of the TSNs connected to EPNs, heating and cooling duties $\varphi_{\left(\mathrm{E}_{j}\right)}^{\mathrm{in}}$ and $\varphi_{\left(\mathrm{E}_{j}\right)}^{\text {out }}$ as well as work duties $\omega_{\left(\mathrm{E}_{j}\right)}^{\text {out }}, \omega_{\left(\mathrm{E}_{j}\right)}^{\text {out }}$. Partial molar and energy balances are formulated for each specific unit type illustrated in Fig. .5 and the results are summarized in Tab. .5. The first column contains the name of the process node, followed by the corresponding stoichiometric equation that links the associated TSNs. The third and fourth columns contain the mass and energy balances.

\section{Mixing Nodes}

Mixing EPNs $\mathrm{L}_{j}$ provide the reactant gas mixtures for $\mathrm{HCN}$ formation, $\mathrm{NH}_{3}$ formation and methanation at equal temperatures and near-ambient pressures. An ideal gas assumption and thus adiabatic mixing is therefore adequate which means that energy balances for mixing nodes are not required.

PMBs of an adiabatic static mixing node $\mathrm{L}_{j}$ are the reverse of the separation edge shown below. One PMB is required for each TSN that is associated with the mixing node. In this example the maximum number of reactants that are mixed is three. The stoichiometric 
coefficients $\chi_{\left(\mathrm{L}_{j}\right)}^{\left(\mathrm{M}_{2}\right)}$ and $\chi_{\left(\mathrm{L}_{j}\right)}^{\left(\mathrm{M}_{3}\right)}$ correspond to the molar fractions of the inlet TSNs $\mathrm{M}_{2}$ and $\mathrm{M}_{3}$ in the outlet TSN M $\mathrm{M}_{1}$. The stoichiometric coefficient of the inlet TSN M $\mathrm{T}_{1}$ equals 1 .

\section{Reactor Nodes}

The reactor nodes $\mathrm{R}_{j}$ of $\mathrm{HCN}$ production that were characterized above - Degussa and Andrussow - are modeled with greater detail than the recycling reactions: the Andrussow reactor is characterized using a steady-state and one-dimensional reactor model in order to quantify heat release and byproduct formation using the system of equations described in literature $^{45}$. The Degussa reactor is described with a rigorous, first principle-based model that takes conduction, convection and radiation inside the reaction compartments into account. This model was recently published in a separate contribution ${ }^{56}$. Reaction kinetic information for both reactors is taken from literature ${ }^{57,45}$. While the Andrussow reactor is operated at a single temperature due to its combustion-like behavior, two reaction temperatures for the Degussa reactor are taken into account: $1200 \mathrm{~K}$ and $1500 \mathrm{~K}$. Reducing the reaction temperature decreases heat demands but increases product purification and recycling cost. Specific heating and cooling duties $\varphi_{\left(\mathrm{R}_{\text {Degussa }}\right)}^{\text {in }}$ and $\varphi_{\left(\mathrm{R}_{\mathrm{Andr}}\right)}^{\text {out }}$ are obtained from the reactor models. The emphasis of this contribution is the resource-efficient process synthesis for HCN and for this reason its chemical formation within the reactor is modeled in great detail. Therefore, all additional reactors that are involved in the recycling pathways - combustion of Andrussow off-gases, $\mathrm{H}_{2}$ combustion, formation of $\mathrm{NH}_{3}$ and $\mathrm{CH}_{4}$ - are described using stoichiometric reactors as shortcut models and the heat duties are obtained from enthalpy differences between in- and outlet mass flows.

Both heating and cooling duties occur and therefore two PMBs and one energy balance are required for the correct EPN description within the FluxMax approach. It is assumed that reactants enter as a mixture and therefore two TSNs participate in each reactor node $\mathrm{R}_{j}$. 


\section{Absorber Process Nodes}

Absorber columns $\mathrm{A}_{j}$ are modeled as adiabatic units and the heat of absorption as well as dissociation is contained in the outlet molar flows. Two different absorbers are present as illustrated in Fig. .5: the absorption of non-reacted $\mathrm{NH}_{3}$ using a diluted solution of $\mathrm{H}_{2} \mathrm{SO}_{4}$ in $\mathrm{H}_{2} \mathrm{O}$ and the consecutive absorption of the product $\mathrm{HCN}$ from the gas stream. Both absorbers are modeled with equilibrium stages and in order to account for dissociation reaction in the liquid phase, the electrolyte non-random-two-liquid model combined with the Redlich-Kwong equation of state (ENRTL-RK) for vapor phase properties is used. Exact design parameters of both absorbers are not available in literature and are approximated as follows:

The absorption of $\mathrm{NH}_{3}$ is based on the neutralization reaction of $\mathrm{NH}_{3}$ in a sulfuric acid solution

$$
\mathrm{NH}_{3}+\mathrm{H}_{3} \mathrm{O}^{+} \rightleftharpoons \mathrm{NH}_{4}^{+}+\mathrm{H}_{2} \mathrm{O}
$$

The equilibrium is entirely on the right hand side and therefore few equilibrium stages are required. The absorber is modeled with 6 equilibrium stages, an entrainer ratio of $e_{\mathrm{A}_{j}}=0.5$ and in- and outlet streams have the following temperatures: $T_{\text {gas,in }}=700 \mathrm{~K}, T_{\text {gas,out }}=346 \mathrm{~K}$, $T_{\text {liq,in }}=340 \mathrm{~K}$ and $T_{\text {liq,out }}=349 \mathrm{~K}$. With these parameters the loss of HCN in the resulting ammonium sulfate solution is minimized and accounts for approximately $4 \%$.

The absorption of HCN relies on the condensation of gaseous HCN and is modeled with 10 equilibrium stages requiring an entrainer ratio of $e_{\mathrm{A}_{j}} \geq 6$. The resulting temperatures of inand outlet streams in order to reduce the content of HCN in the gas stream to trace amounts are: $T_{\text {gas }, \text { in }}=313 \mathrm{~K}, T_{\text {gas }, \text { out }}=295 \mathrm{~K}, T_{\text {liq,in }}=295 \mathrm{~K}$ and $T_{\text {liq }, \text { out }}=307 \mathrm{~K}$.

Four associated TSNs are present in the description of an absorber EPN: the inlet TSN mixture, the entrainer at an entrainer-to-feed ratio $e_{\left(\mathrm{A}_{j}\right)}$ and the two outlet TSNs. Consequently, 
four PMBs are formulated and no energy balance is required for an adiabatic absorber EPN.

\section{Distillation Process Nodes}

Distillation column nodes $\mathrm{S}_{j}$ are described with the Winn-Underwood-Gilliland shortcut model in ASPEN Plus. The minimum number of stages and reflux ratio and the required reflux ratio for a specified number of stages and distillate composition are obtained using the ENRTL-RK property model. This property method is selected because trace amounts of $\mathrm{H}_{2} \mathrm{SO}_{4}$ must be present to maintain the $\mathrm{pH}$ of the dilute $\mathrm{HCN}$ mixture close to two for two reasons: to avoid dissociation of the target molecule and to prevent its subsequent exothermal polymerization reactions. The property data for this mixture within Aspen is taken from the Chemical Engineer's Handbook ${ }^{58}$. In order to achieve a recovery of HCN of $99.9 \%$, the minimum number of stages is 7 at a reflux ratio of 0.72 . Four different distillation columns are taken into account in the process superstructure: 8, 11, 14 and 17 stages.

Three associated TSNs are connected with a distillation process node - feed, distillate and bottom product - and therefore three PMBs are required as shown in Tab. .5. In addition to that, two energy balance equations, Eq. (5b) and Eq. (5c) are required to account for reboiler and condenser duties.

\section{Hydrogen and Methane Separator Nodes}

The gas separations of $\mathrm{H}_{2}$ and $\mathrm{CH}_{4}$ in order to recycle byproduct and non-converted reactants in Fig. .5 are modeled with a shortcut model because they are part of the recycle section of the superstructure: the separation work duty is estimated using the molar Gibbs enthalpy of mixing $\Delta_{\mathrm{M}} g$ of the TSN inlet assuming an ideal gas mixture (Eq. (.1)).

$$
\Delta_{\mathrm{M}} g:=\sum_{\alpha} R T x_{\alpha} \ln x_{\alpha}
$$


The separation duty is then calculated as the Gibbs enthalpy of mixing multiplied with an energetic efficiency factor according to Tab. .2.

Both gas separations are modelled with a generic unit type $\mathrm{G}_{j}$ with three PMBs and two energy balances (Eq. (5a), Eq. (5b)).

\section{Temperature State Changer Process Nodes}

Temperature state changer process nodes $\mathrm{D}_{j}$ are required in order to link TSNs of similar composition among EPNs. Isobaric change of temperature is assumed for the participating TSNs and the heating or cooling duties are the enthalpy difference between in- and outlet

TSNs of the economizer, $\varphi_{\left(\mathrm{D}_{j}\right)}^{\text {in/out }}:=\Delta h_{\left(\mathrm{M}_{i+1}\right)}^{\left(\mathrm{M}_{i}\right)}$. The condenser is modelled in a similar way except that it has two outward-pointing TSN mass flows, because the separation of $\mathrm{H}_{2} \mathrm{O}$ results from cooling the inlet stream entering via the inlet TSN.

Two PMBs for regular temperature change and three PMBs for condensers are required and either Eq. (5b) or Eq. (5c) to account for heating and cooling duties. Stoichiometric coefficients of temperature changer process nodes equal one because in- and outlet mass flows are equal. 
Table .1: Temperature Conditions for Classification of Heat Integration Possibilities

\begin{tabular}{|c|c|c|c|c|c|}
\hline Case & \multicolumn{4}{|c|}{ Condition } & Heat Integration \\
\hline \multicolumn{6}{|c|}{ Cold Fluxes } \\
\hline I & i) & $T_{U_{l}} \geq$ & $T_{\text {cold, out }}$ & $+\Delta T_{\min }$ & total \\
\hline \multirow[t]{2}{*}{ II } & i) & $T_{U_{l}}<$ & $T_{\text {cold, out }}$ & & \multirow{2}{*}{ partial } \\
\hline & ii) & $T_{U_{l}}>T_{\text {cold }}$ & & $+\Delta T_{\min }$ & \\
\hline III & i) & $T_{U_{l}} \leq T_{\text {cold }}$ & & $+\Delta T_{\min }$ & infeasible \\
\hline \multicolumn{6}{|c|}{ Hot Fluxes } \\
\hline I & i) & $T_{U_{l}}+\Delta T_{\min }$ & $\leq$ & $T_{\text {hot, out }}$ & total \\
\hline \multirow[t]{2}{*}{ II } & i) & $T_{U_{l}}+\Delta T_{\min }$ & $>$ & $T_{\text {hot, out }}$ & \multirow[t]{2}{*}{ partial } \\
\hline & ii) & $T_{U_{l}}+\Delta T_{\min }$ & $<T_{\mathrm{hot}, \mathrm{in}}$ & & \\
\hline III & i) & $T_{U_{l}}+\Delta T_{\min }$ & $\geq T_{\mathrm{hot}, \mathrm{in}}$ & & infeasible \\
\hline
\end{tabular}


Table .2: Case study parameters for simultaneous process synthesis and heat integration for the production of HCN.

\begin{tabular}{|c|c|c|c|}
\hline Parameter & Symbol & Unit & Value \\
\hline \multicolumn{4}{|l|}{ simulation parameters } \\
\hline separation efficiency & $\eta$ & - & 0.01 \\
\hline minimum temperature difference & $\Delta T_{\min }$ & $\mathrm{K}$ & 20 \\
\hline utility temperatures & $\mathbf{T}_{\left(\mathrm{U}_{l}\right)}$ & $\mathrm{K}$ & {$[290,500,1600]^{\top}$} \\
\hline lower heating value of $\mathrm{CH}_{4}$ & $h_{\mathrm{CH}_{4}}$ & $\mathrm{~kJ} / \mathrm{mol}$ & 800 \\
\hline \multicolumn{4}{|l|}{ cost values } \\
\hline work duty & $p_{\dot{W}_{\mathrm{ext}}}$ & $\mathrm{EUR} / \mathrm{kJ}$ & $2.8 \times 10^{-5}$ \\
\hline cooling duty & $p_{\dot{Q}^{\text {ext }, \text { out }}}$ & $\mathrm{EUR} / \mathrm{kJ}$ & $1.7 \times 10^{-6}$ \\
\hline purchase methane & $p_{\mathrm{CH}_{4}}$ & $\mathrm{EUR} / \mathrm{mol}$ & $1.6 \times 10^{-3}$ \\
\hline purchase ammonia & $p_{\mathrm{CH}_{4}}$ & $\mathrm{EUR} / \mathrm{mol}$ & $1.5 \times 10^{-2}$ \\
\hline purchase hydrogen cyanide & $p_{\mathrm{CH}_{4}}$ & $\mathrm{EUR} / \mathrm{mol}$ & - \\
\hline purchase air & $p_{\text {air }}$ & $\mathrm{EUR} / \mathrm{mol}$ & 0 \\
\hline purchase hydrogen & $p_{\mathrm{H}_{2}}$ & $\mathrm{EUR} / \mathrm{mol}$ & $1.0 \times 10^{-3}$ \\
\hline purchase water & $p_{\mathrm{H}_{2} \mathrm{O}, \mathrm{in}}$ & $\mathrm{EUR} / \mathrm{mol}$ & $1.7 \times 10^{-5}$ \\
\hline purchase carbon dioxide & $p_{\mathrm{CO}_{2}, \text { in }}$ & $\mathrm{EUR} / \mathrm{mol}$ & $1.4 \times 10^{-3}$ \\
\hline purchase carbon monoxide & $p_{\mathrm{CO}}$ & $\mathrm{EUR} / \mathrm{mol}$ & $2.6 \times 10^{-3}$ \\
\hline discharge water & $p_{\mathrm{H}_{2} \mathrm{O}, \text { out }}$ & $\mathrm{EUR} / \mathrm{mol}$ & $-2.5 \times 10^{-5}$ \\
\hline discharge carbon dioxide & $p_{\mathrm{CO}_{2}, \text { out }}$ & $\mathrm{EUR} / \mathrm{mol}$ & $-4.8 \times 10^{-4}$ \\
\hline
\end{tabular}


Table .3: Objective functions used throughout this work.

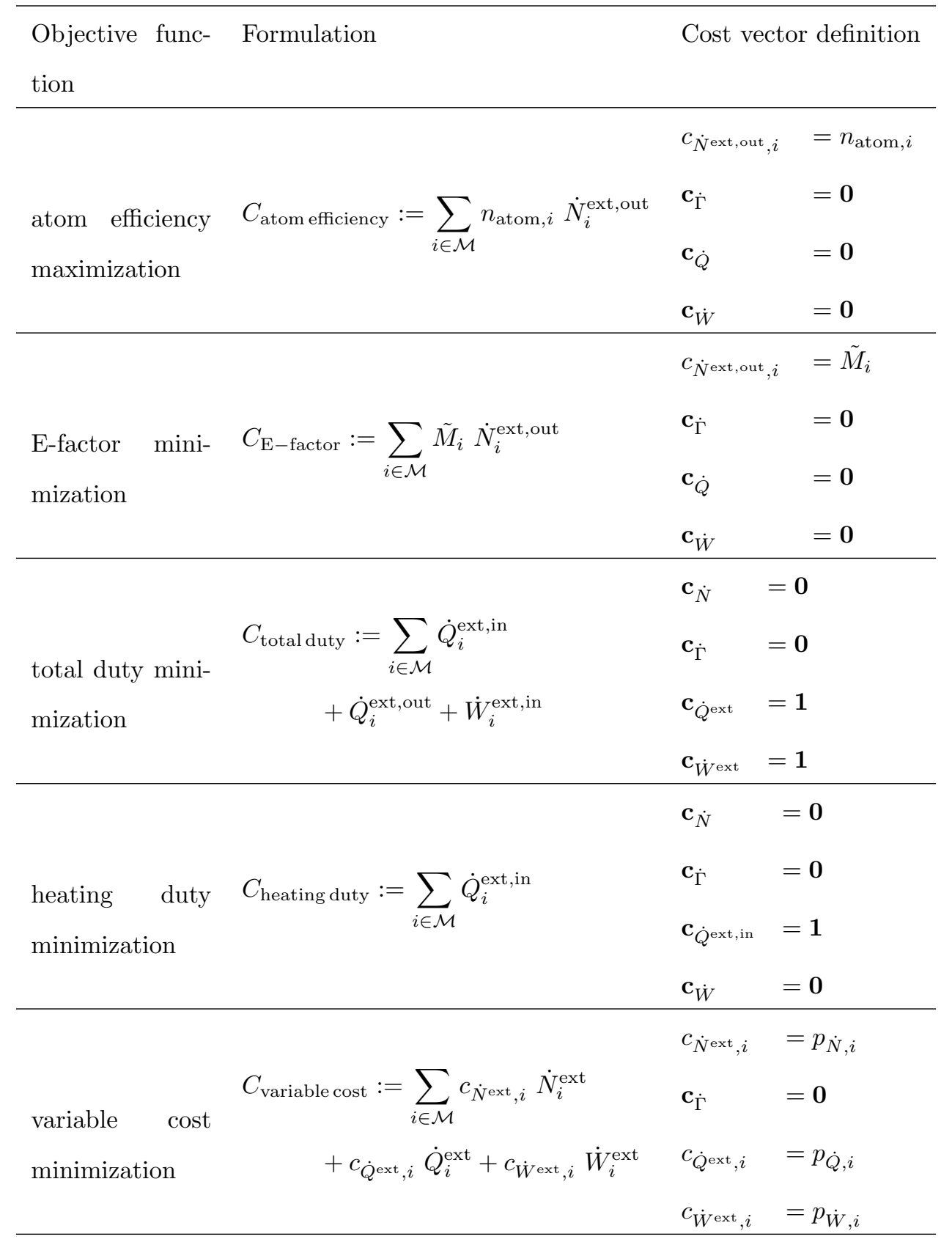

This article is protected by copyright. All rights reserved. 
Table .4: Relative changes of objective values of scenarios $i$ compared with objective values of the base case process.

\begin{tabular}{llllll}
\hline & $\mathrm{R}_{(1)}$ & $\mathrm{R}_{(1)}(\mathrm{HI})$ & $\mathrm{R}_{(1)}+\mathrm{NH}_{3}(\mathrm{HI})$ & $\alpha(\mathrm{HI})$ & $\beta(\mathrm{HI})$ \\
\hline$\frac{\eta_{\text {atom }}(i)}{\eta_{\text {atom }}\left(\mathrm{R}_{(1)}\right)}-1 / \%$ & 0 & 0 & +19.3 & +39.5 & 0 \\
$\frac{E_{\text {Sheldon }}(i)}{E_{\text {Sheldon }}\left(\mathrm{R}_{(1)}\right)}-1 / \%$ & 0 & 0 & -4.0 & -7.5 & +35.2 \\
$\frac{q^{\text {ext, in }}(i)}{q^{\text {ext, in }}\left(\mathrm{R}_{(1)}\right)}-1 / \%$ & 0 & -18.6 & -18.6 & -18.6 & -48.8 \\
$\frac{\sum_{j} q^{\text {ext }, \mathrm{j}}+w^{\text {ext }, \mathrm{j}}(i)}{\sum_{j} q^{\text {ext }, \mathrm{j}}+w^{\text {ext }, \mathrm{j}}\left(\mathrm{R}_{(1)}\right)}-1 / \%$ & 0 & -21.8 & +14.9 & +48.4 & +28.7 \\
$\frac{C_{\text {var }}(i)}{C_{\text {var }}\left(\mathrm{R}_{(1)}\right)}-1 / \%$ & 0 & -2.0 & -66.7 & -54.6 & -67.6 \\
\hline
\end{tabular}




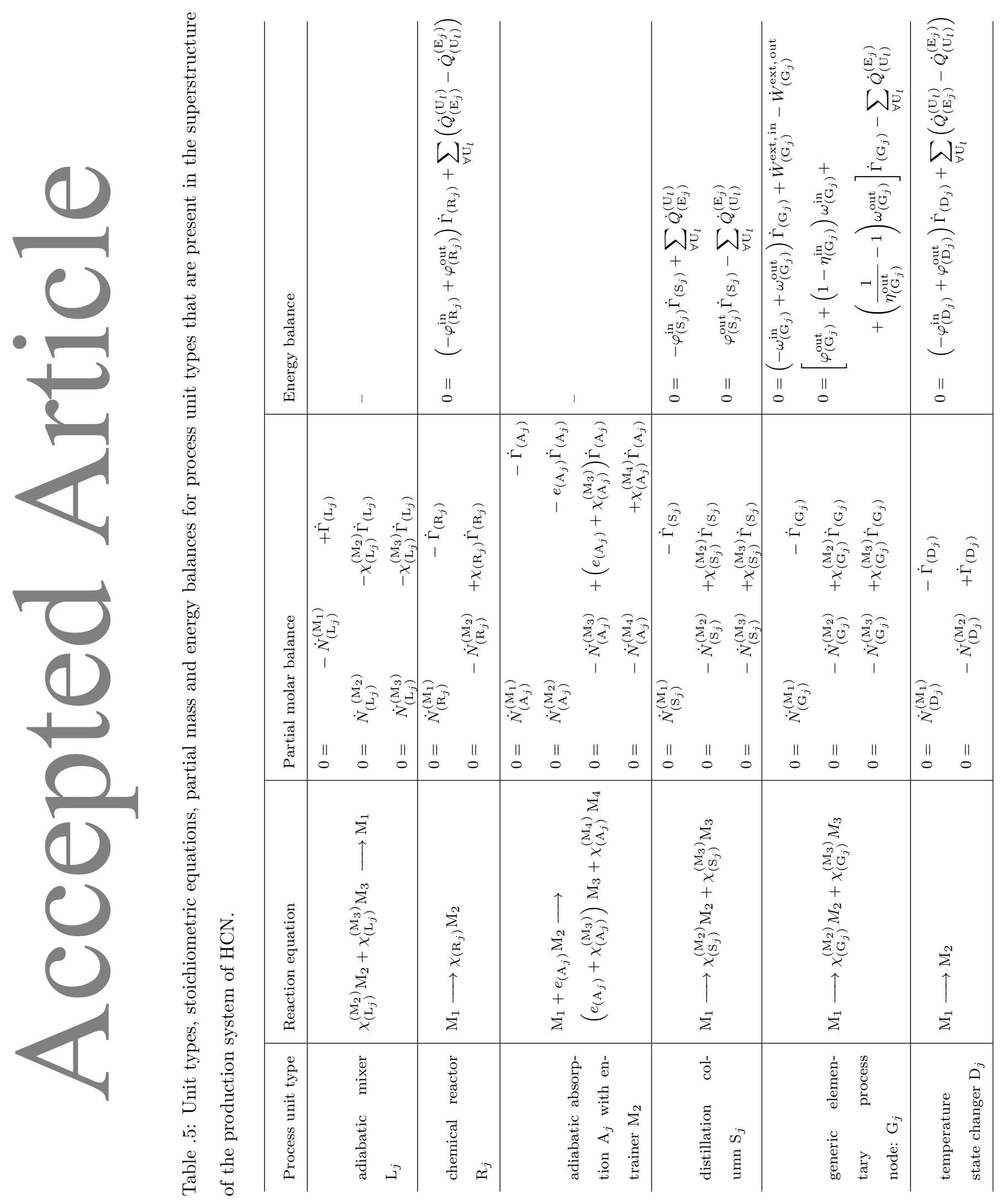




\section{List of Figures}

.1 Degussa (A, Eq. (1a)) and Andrussow (B, Eq. (1b)) reactors to synthesize HCN. Endothermic Degussa reactors produce a higher purity product than Andrussow reactors that are exothermic instead. . . . . . . . . . . . . . .

.2 Illustration of the three-step FluxMax approach (left) for process design with simultaneous energy integration (right): discretization of the thermodynamic state space for two arbitrary thermodynamic properties $\zeta_{1}$ and $\zeta_{2}$ (I), modeling of elementary processes respective process units leading to a superstructure (II) and network mass and energy flow optimization representing process design and integration (III) $\ldots \ldots \ldots \ldots \ldots \ldots \ldots$

.3 Grid of thermodynamic state points (A) in the thermodynamic state space with $p, T$ and $\mathbf{x}$ coordinates. Thermodynamic substance nodes (green) are linked via elementary process functions (orange): isobaric heating $\left(\mathrm{EPF}_{4}\right)$ and cooling $\left(\mathrm{EPF}_{3}\right)$, isobaric-isothermic absorption $\left(\mathrm{EPF}_{1}\right)$ and isobaric distillation $\left(\mathrm{EPF}_{2}\right)$. The digraph representation for EPFs that link two TSN (green circles) $\mathrm{M}_{i}$ and $\mathrm{M}_{i+1}$ via an elementary process node $\mathrm{E}_{j}$ (yellow circle) is illustrated on the right (B). Work utility nodes (red circles) and heat utility nodes (blue circles) supply the EPN with duties. Work fluxes (red arrows), heat fluxes (blue arrows) and molar fluxes (black arrows) link the four node types. The conversion is described by a reaction equation that is characterized by the Generalized Unit Number $\dot{\Gamma}_{\left(\mathrm{E}_{j}\right)} \ldots \ldots \ldots \ldots \ldots \ldots$

.4 Illustration of heat integration inequality constraints for heat integration via utilities as summarized in Tab. .1 (cold fluxes: blue, full lines; hot fluxes: red, dashed lines): cold fluxes are heated by the hot utility $\mathrm{U}_{l}$ (left) and hot fluxes are cooled by a cold utility (right). I, II and III represent totally and partially feasible as well as infeasible heat exchange. . . . . . . . . . . . 
.5 Schematic flowsheet of process synthesis for the production of HCN (top section) including the selection of the process route (Degussa or Andrussow) and design decisions such as number of trays of the final distillation column. The bottom section illustrates three possible recycling possibilities upon separation of $\mathrm{H}_{2}$ from the byproduct gas stream: energetic coupling via combustion of $\mathrm{H}_{2}$ (I) and two synthesis routes using the surplus $\mathrm{H}_{2}$ towards $\mathrm{NH}_{3}$ (II) and $\mathrm{CH}_{4}$ (III). Additionally, for low temperatures of the BMA reactor, $\mathrm{CH}_{4}$ may be recycled and additional exhaust gases of the Andrussow such as CO require combustion prior to release to the environment. Arrows correspond to mass (black), heat (blue) and work (red) fluxes. Units hatched outside indicate adiabatic units. . . . . . . . . . . . . . . . .

.6 Weighted optimization of two targets: atom efficiency versus total energy duties (A), atom efficiency versus heating duties (B), atom efficiency versus Efactor $(\mathrm{C})$ and atom efficiency versus total variable cost (D). A, B form Pareto curves where the front is indicated with a dotted line; C, D are not competing objectives and form no Pareto front. Shapes correspond to the four distillation column process nodes and colors to the three reactor process nodes highlighted at the top. Symbols that are filled with color include heat integration in their calculation, symbols that are filled with black color highlight results without simultaneous heat integration. . . . . . . . . . . . . . . .

Optimal atom economy (A), E-factor (B), duties (C) and variable cost (D). The legend of the 12 scenarios corresponds to the one of Fig. .6: the symbol and background color indicate the reactor node and the shape denotes the distillation column node. Edge gray shade denotes the type of property and the filling with/without heat integration. . . . . . . . . . . . . . 
.8 Illustration of the impact of heat integration and three different recycle pathways on the three available reactor nodes (background color) and on the five objectives: atom economy (A), E-factor (B), total (C) and heating (D) duties as well as total variable cost (E). Bars in each group represent (from left to right): no recycling and no heat integration, no recycling with heat integration, combustion of $\mathrm{H}_{2}$ with heat integration, production of $\mathrm{NH}_{3}$ with heat integration and $\mathrm{CH}_{4}$ production with heat integration. . . . . . . . .

.9 Pareto optimal results for the entire process scheme of Fig. .5: Symbols denote recycling pathways and colors the reactor type. Pareto fronts are indicated with a dashed line (no heat integration) and a dotted line (including heat integration). Four scenarios are compared: atom efficiency versus total duty (A), atom efficiency versus heating duty (B), total variable cost versus total duty $(\mathrm{C})$ and total variable cost versus heating duty $(\mathrm{D}) \ldots \ldots \ldots$. . . . .

.10 Flowsheets of the two novel process designs for production of HCN from Fig. .9. Combination of $\mathrm{NH}_{3}$ and $\mathrm{CH}_{4}$ production for minimal atom efficiency at low energy duties (A) and parallel operation of high temperature Degussa and Andrussow reactors with $\mathrm{NH}_{3}$ production for minimal total variable cost and heating duties. Atom efficiencies (C), E-factors (D), heating, cooling, work duties (E) and variable cost (F) of the two designs are presented at the bottom. . . . . . . . . . . . . . . . . 

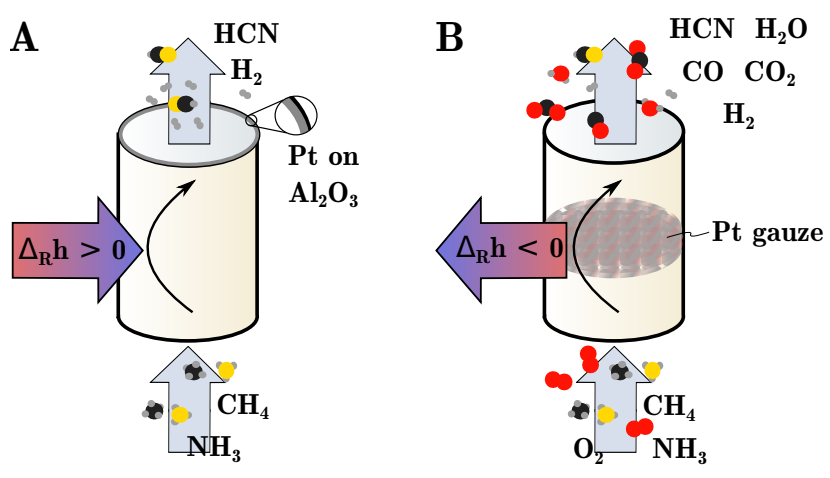

Figure .1: Degussa (A, Eq. (1a)) and Andrussow (B, Eq. (1b)) reactors to synthesize HCN. Endothermic Degussa reactors produce a higher purity product than Andrussow reactors that are exothermic instead. 


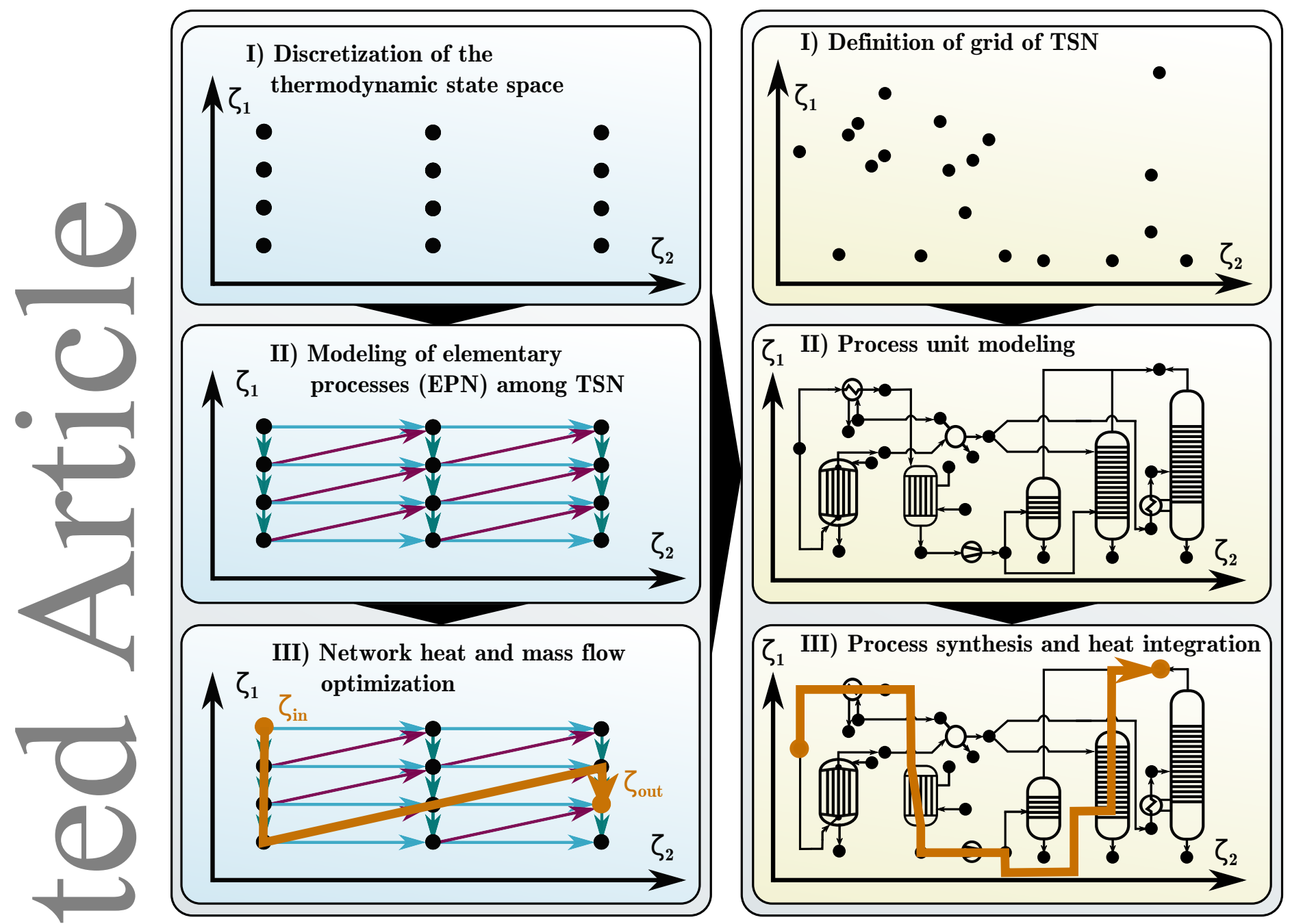

Figure .2: Illustration of the three-step FluxMax approach (left) for process design with simultaneous energy integration (right): discretization of the thermodynamic state space for two arbitrary thermodynamic properties $\zeta_{1}$ and $\zeta_{2}$ (I), modeling of elementary processes respective process units leading to a superstructure (II) and network mass and energy flow optimization representing process design and integration (III). 


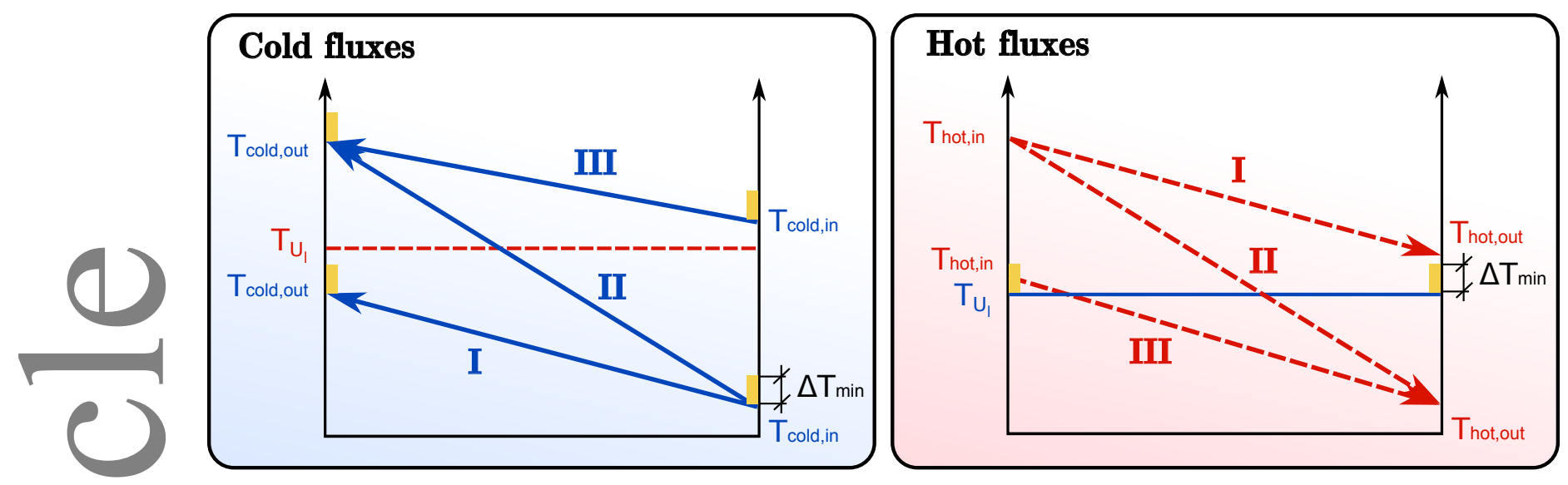

Figure .4: Illustration of heat integration inequality constraints for heat integration via utilities as summarized in Tab. .1 (cold fluxes: blue, full lines; hot fluxes: red, dashed lines): cold fluxes are heated by the hot utility $\mathrm{U}_{l}$ (left) and hot fluxes are cooled by a cold utility (right). I, II and III represent totally and partially feasible as well as infeasible heat exchange. 

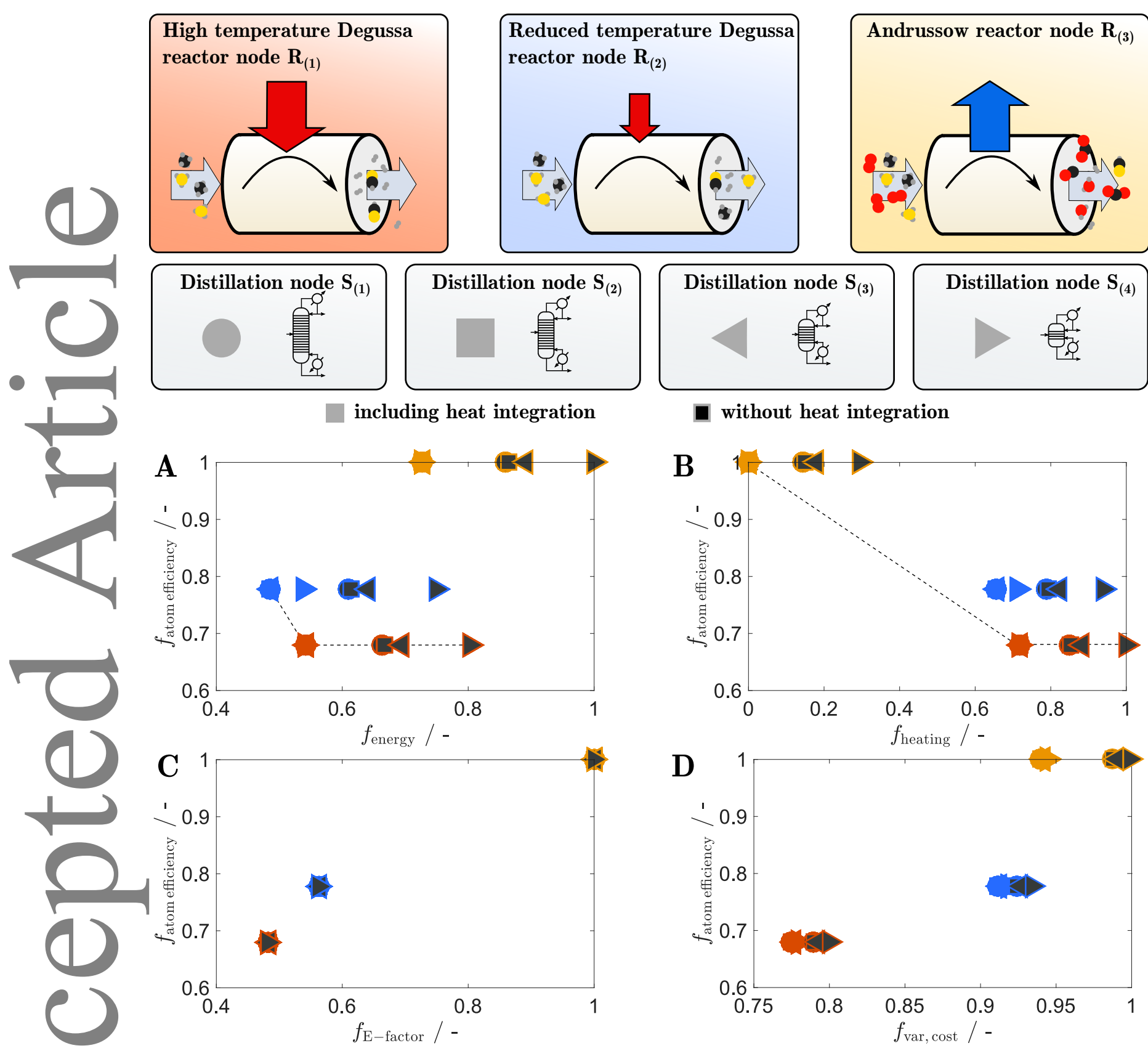

Figure .6: Weighted optimization of two targets: atom efficiency versus total energy duties (A), atom efficiency versus heating duties (B), atom efficiency versus E-factor (C) and atom efficiency versus total variable cost (D). A, B form Pareto curves where the front is indicated with a dotted line; C, D are not competing objectives and form no Pareto front. Shapes correspond to the four distillation column process nodes and colors to the three reactor process nodes highlighted at the top. Symbols that are filled with color include heat integration in their calculation, symbols that are filled with black color highlight results without simultaneous heat integration. 


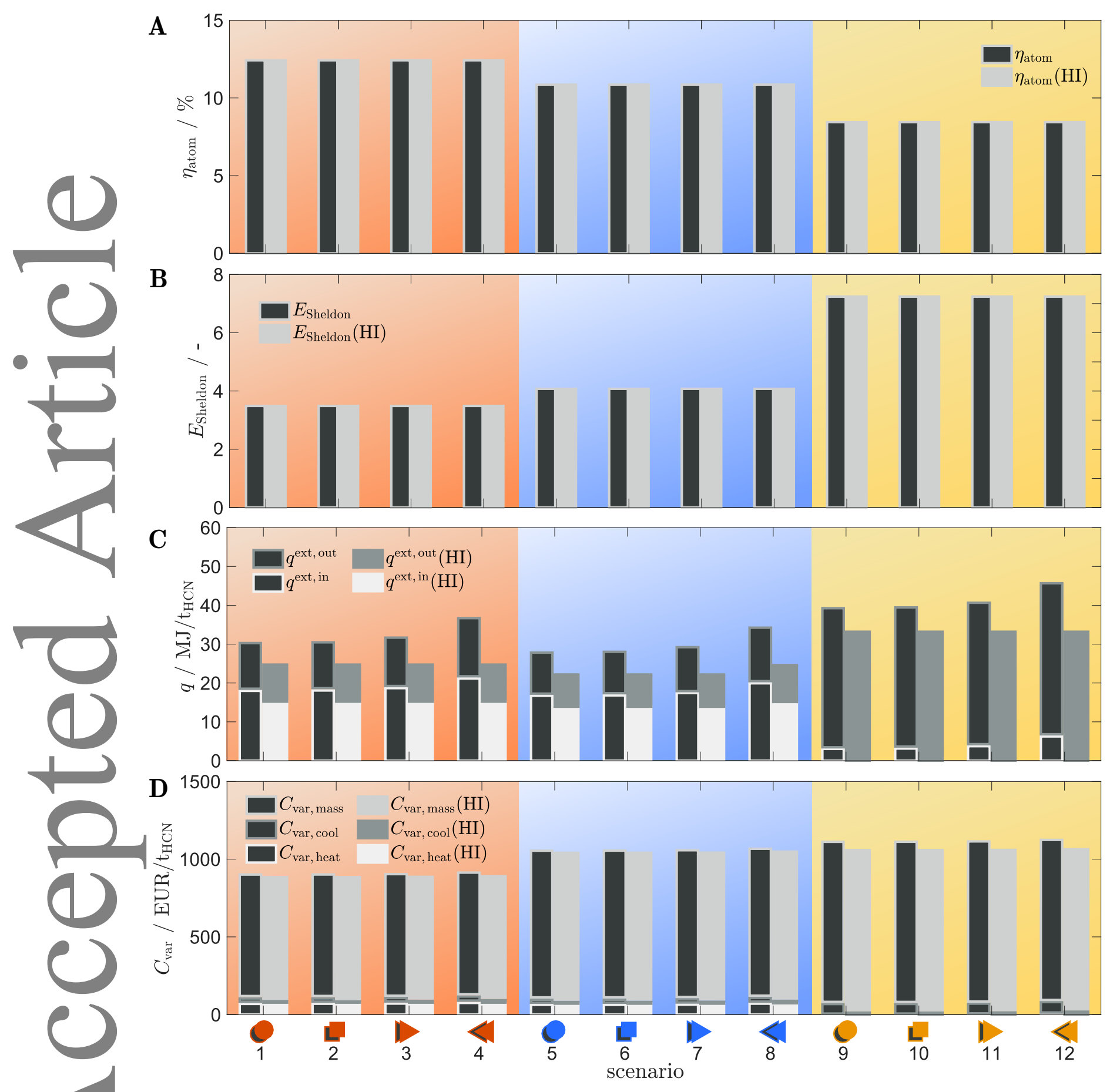

Figure .7: Optimal atom economy (A), E-factor (B), duties (C) and variable cost (D). The legend of the 12 scenarios corresponds to the one of Fig. .6: the symbol and background color indicate the reactor node and the shape denotes the distillation column node. Edge gray shade denotes the type of property and the filling with/without heat integration. 
A

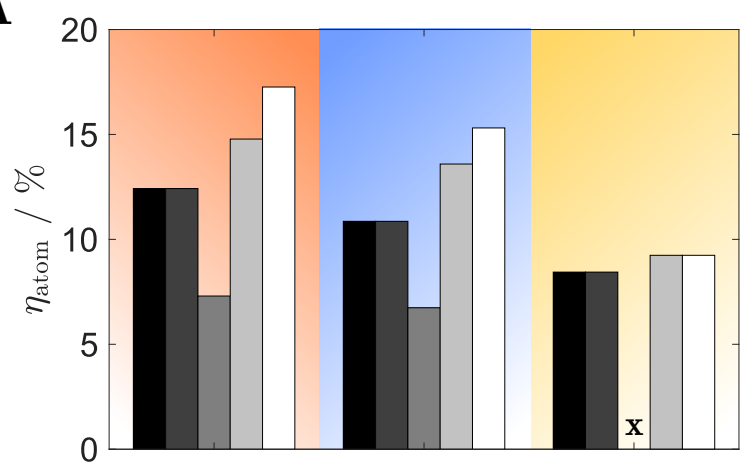

C

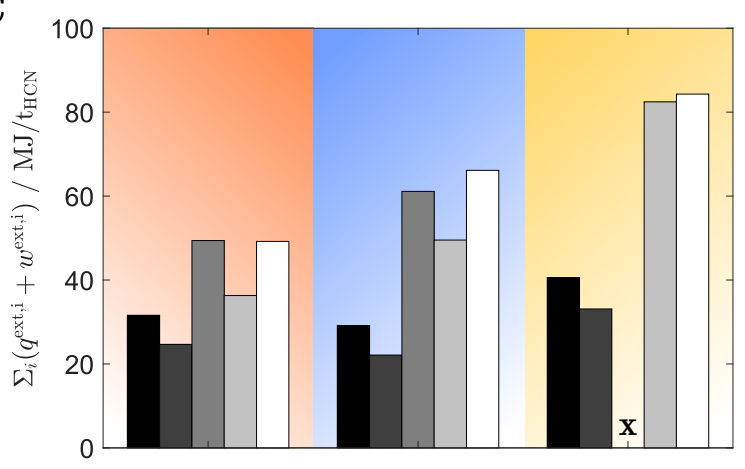

$\mathbf{E}$

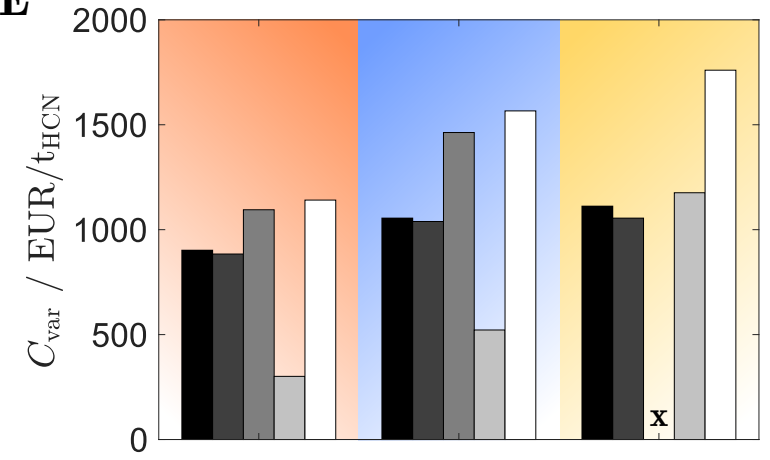

B

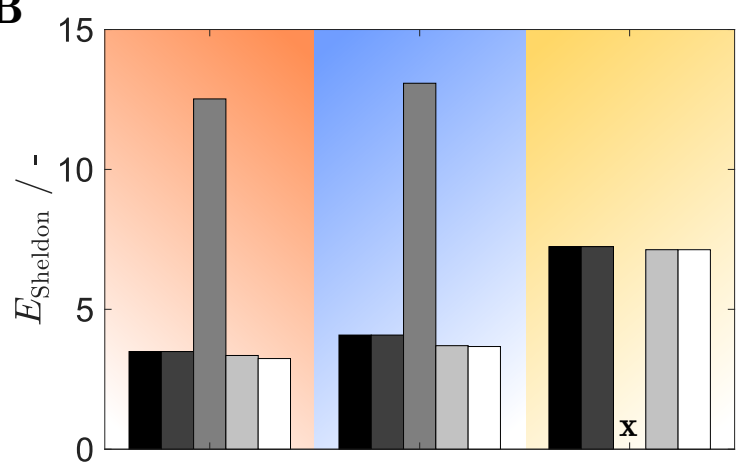

D
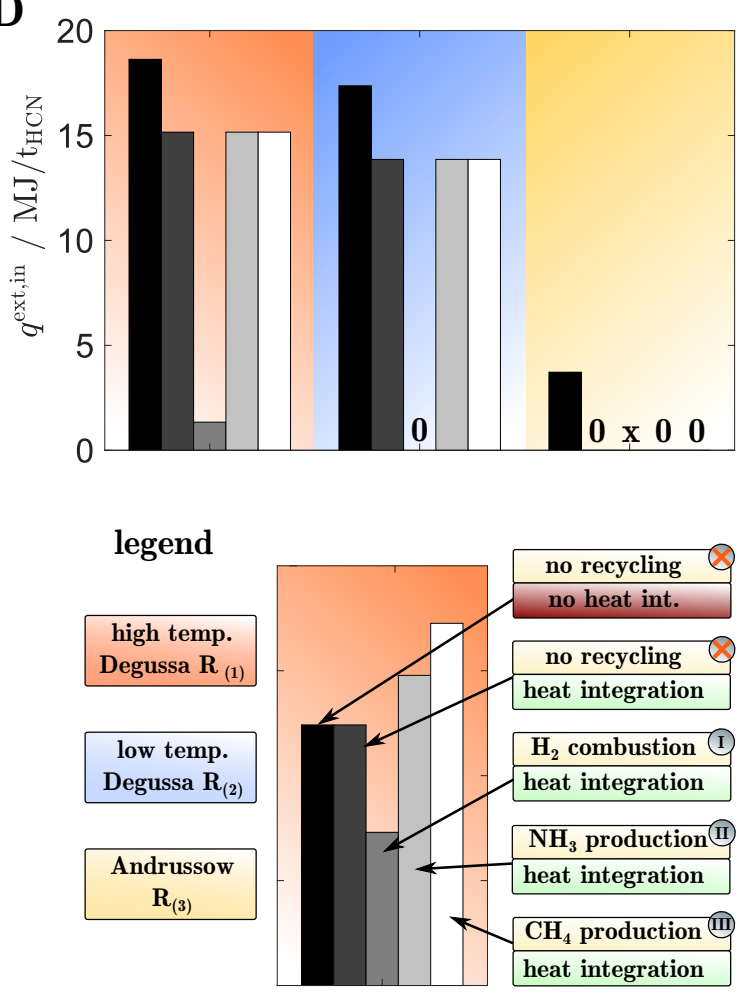

Figure .8: Illustration of the impact of heat integration and three different recycle pathways on the three available reactor nodes (background color) and on the five objectives: atom economy (A), E-factor (B), total (C) and heating (D) duties as well as total variable cost (E). Bars in each group represent (from left to right): no recycling and no heat integration, no recycling with heat integration, combustion of $\mathrm{H}_{2}$ with heat integration, production of $\mathrm{NH}_{3}$ with heat integration and $\mathrm{CH}_{4}$ production with heat integration. 

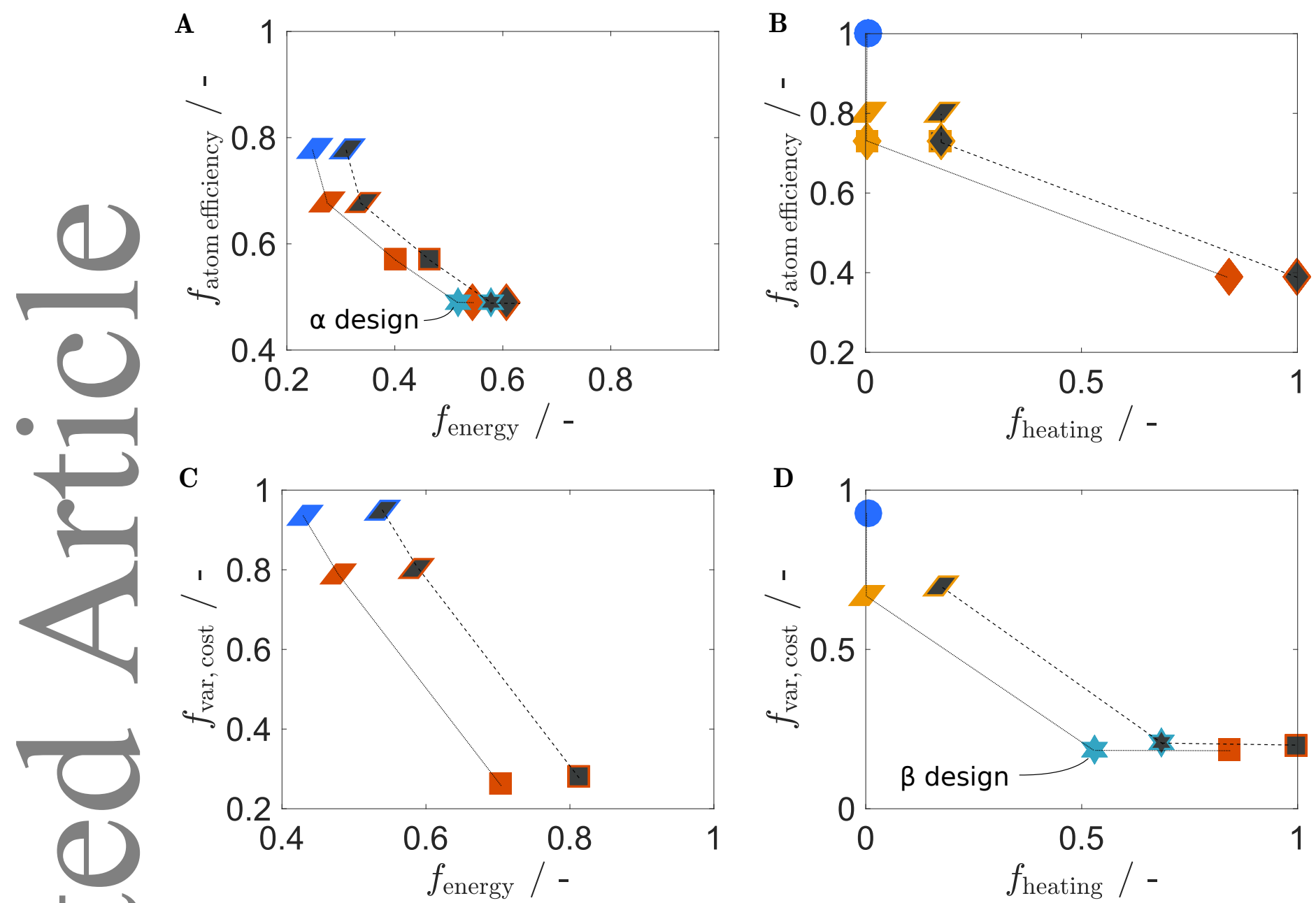

\begin{tabular}{|l|l|l|l|l|}
\hline $\mathbf{H}_{2}$ combustion & $\mathrm{NH}_{3}$ production & $\mathbf{C H}_{4}$ production & Any combination & No recycling \\
\hline High temperature Degussa $\mathbf{R}_{(1)}$ & Low temperature Degussa $\mathbf{R}_{(2)}$ & Andrussow $\mathbf{R}_{(3)}$ & Any combination \\
\hline including heat integration & $\mathbf{n}$ without heat integration \\
\hline
\end{tabular}

Figure .9: Pareto optimal results for the entire process scheme of Fig. .5: Symbols denote recycling pathways and colors the reactor type. Pareto fronts are indicated with a dashed line (no heat integration) and a dotted line (including heat integration). Four scenarios are compared: atom efficiency versus total duty (A), atom efficiency versus heating duty (B), total variable cost versus total duty $(\mathrm{C})$ and total variable cost versus heating duty (D). 

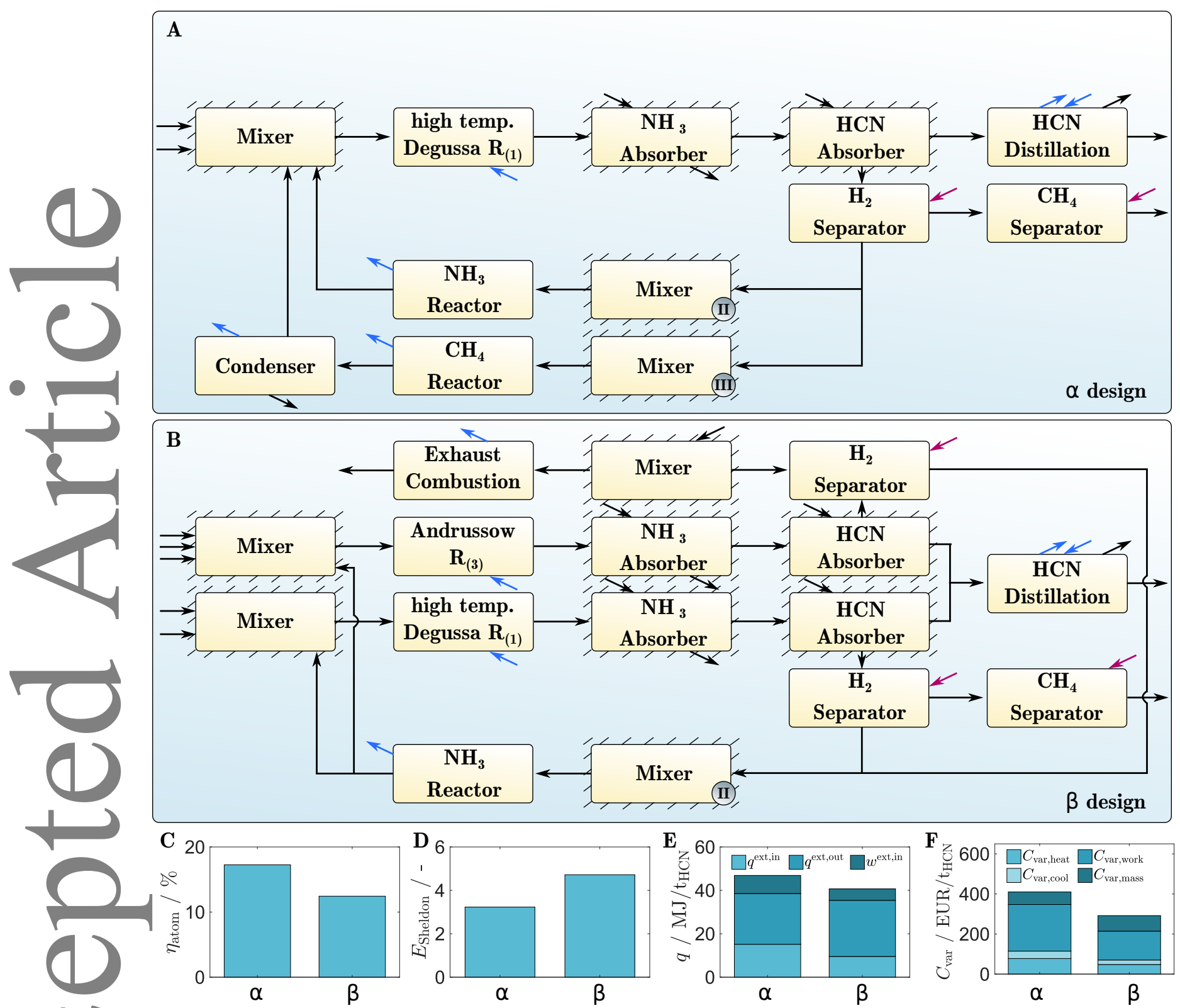

Figure .10: Flowsheets of the two novel process designs for production of HCN from Fig. .9. Combination of $\mathrm{NH}_{3}$ and $\mathrm{CH}_{4}$ production for minimal atom efficiency at low energy duties (A) and parallel operation of high temperature Degussa and Andrussow reactors with $\mathrm{NH}_{3}$ production for minimal total variable cost and heating duties. Atom efficiencies (C), E-factors (D), heating, cooling, work duties (E) and variable cost (F) of the two designs are presented at the bottom. 